\title{
ESTUDIO DEL PERFIL SOCIOCULTURAL Y ALIMENTARIO DE LOS USUARIOS DE SERVICIOS SOCIALES DE MELILLA
}

Trabajo de Fin de Máster

Curso $2019-2020$

Yasmin Mohamed Ziyani

Tutores: Miguel Ángel Montero Alonso y Emilio González Jiménez 


\section{DECLARACIÓN DE ORIGINALIDAD}

Melilla, a 14 de septiembre de 2020

D./D. ${ }^{a}$ YASMIN MOHAMED ZIYANI con DNI n 45303384-P, alumno/a del Máster Universitario en Diversidad Cultural. Un enfoque multidisciplinar y transfronterizo garantiza, al firmar este Trabajo Fin de Máster, que este trabajo ha sido realizando respetando los derechos de otros autores a ser citados, cuando se han utilizado sus materiales, resultados o publicaciones.

EL ALUMNO

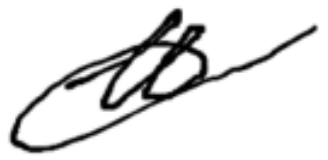

Fdo.: YASMIN MOHAMED ZIYANI 


\section{Agradecimientos}

En primer lugar quiero mostrar mi agradecimiento a mis tutores Miguel Ángel Montero Alonso y Emilio González Jiménez, por su predisposición e implicación durante el desarrollo de este arduo trabajo.

Al director de Servicios Sociales J.A, por hacer posible la investigación.

A mi familia y amigos, por el apoyo incondicional que me brindan siempre que me propongo nuevas metas. 


\section{RESUMEN}

Introducción: La crisis financiera del 2008 produjo una grave recesión en España que conllevó a la adopción de medidas austeras y reformas del mercado de trabajo, con la consiguiente precarización laboral, aumento del desempleo, e incremento de la pobreza y las desigualdades sociales. Tal situación, condujo a buena parte de la ciudadanía española a recurrir a los Servicios Sociales, los cuales han experimentado un aumento de la demanda y cambio de perfil de los usuarios. Asimismo, la crisis ha provocado modificaciones del patrón alimentario, malos hábitos dietéticos y carencias nutricionales. Objetivos: Definir el perfil de los usuarios de Servicios Sociales de Melilla, determinar la relación entre las características sociodemográficas y culturales y el estilo de vida, y evaluar el patrón de consumo alimentario y grado de cumplimiento de las recomendaciones dietéticas. Metodología: Diseño metodológico observacional, transversal y descriptivo. La muestra fue seleccionada de manera accidental y estuvo conformada por 50 participantes de dos centros de Servicios Sociales, con edades comprendidas entre los 26 y 76 años de los cuales 33 fueron mujeres y 17 hombres. Los datos fueron recabados mediante una encuesta ad hoc que incluía variables sociodemográficas, antecedentes y hábitos de salud, estilo de vida y pautas de comportamiento alimentario. Resultados: Existe un predominio de mujeres en los Servicios Sociales mayoritariamente de 45 a 65 años, desempleadas y con hijos a cargo. El estilo de vida mostró diferencias entre comunidades, siendo más óptimo el de la cultura bereber y más sedentario el de la cultura española. El patrón dietético de la población es poco saludable e incumple por defecto las recomendaciones dietéticas, observándose mayores carencias en la cultura árabe, hombres y mayores de 65, y una ingesta más excesiva de alimentos de consumo ocasional en la cultura española, hombres y jóvenes de 18 a 30 años. Conclusiones: El perfil de los usuarios de Servicios Sociales de Melilla es principalmente femenino y de origen bereber. La percepción subjetiva sobre el estilo de vida es positiva pero no se ajusta a la realidad. Existe un bajo aporte de alimentos esenciales y un patrón dietético mejorable.

Palabras claves: Crisis, desigualdades sociales, patrón alimentario, pobreza, Servicios Sociales. 


\section{ABSTRACT}

Introduction: The 2008 financial crisis caused a severe recession in Spain which led to the implementation of austere measures and labour market reforms, and the consequent job precariousness, rising unemployment, and increasing poverty and social inequalities. In such a situation, many Spanish citizens were forced to resort to Welfare Services, which have experienced an increase in demand and a change in beneficiary profiles. The crisis has also provoked changes in the eating pattern, poor dietary habits and nutritional deficiencies. Objectives: To define beneficiaries profile of Welfare Services from Melilla, to establish the relationship between socio-demographic and cultural characteristics and lifestyle, and to evaluate eating habits and the degree of compliance with nutritional recommendations. Methodology: Observational, crosssectional and descriptive methodological design. The sample was selected accidentally and was configured by 50 participants from two Social Welfare centers, aged between 26 and 76 years from which 33 were women and 17 men. The data were collected through an ad hoc survey that included sociodemographic variables, health history and habits, lifestyle, and eating behavior patterns. Results: There is a female predominance in Welfare Services mostly from 45 to 65 years old, unemployed and with dependent children. The lifestyle showed differences between communities, being the Berber culture more optimal and the Spanish culture more sedentary. The eating pattern of the population is unhealthy and does not comply with dietary recommendations; observing greater deficiencies in the Arab culture, men and adults over 65; and more excessive intake of foods for occasional consumption in the Spanish culture, men and young people from 18 to 30 years old. Conclusions: The users profile of Welfare Services in Melilla is mainly female and of Berber origin. The subjective perception of lifestyle is positive but does not adjust to reality. There is a low contribution of essential foods and a improvable dietary pattern.

Key words: Crisis, social inequalities, eating pattern, poverty, Welfare Services. 


\section{ÍNDICE}

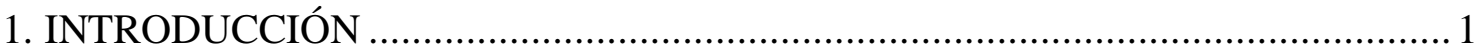

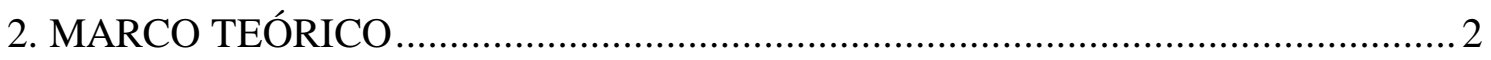

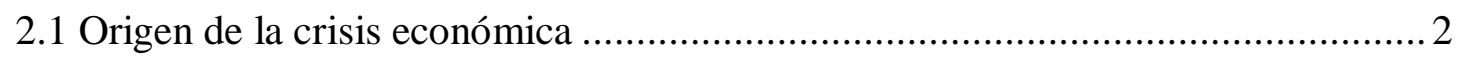

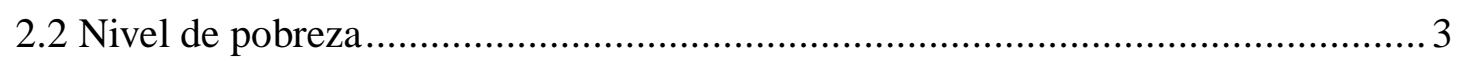

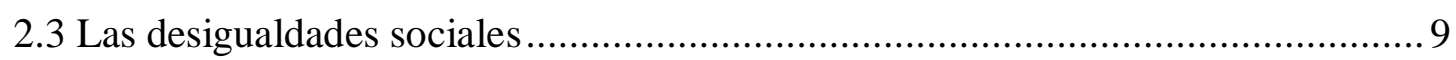

2.4 El Estado de Bienestar y los Servicios Sociales .............................................. 15

2.5 El perfil de los usuarios de Servicios Sociales ............................................ 19

2.6 La alimentación en tiempos de crisis ...........................................................2 20

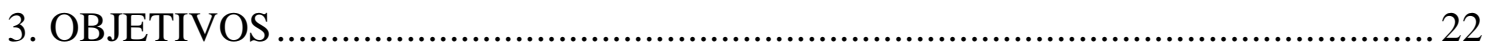

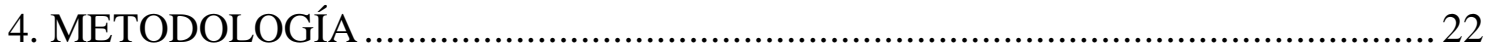

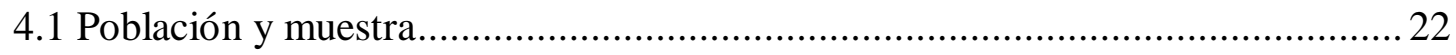

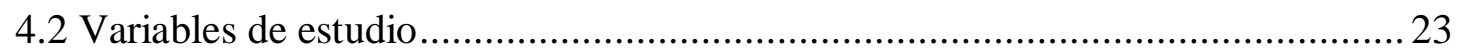

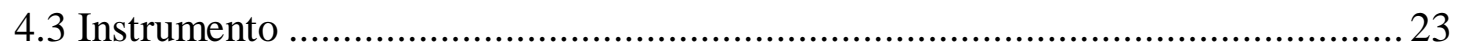

4.4 Técnica de recogida y análisis de datos ..................................................... 23

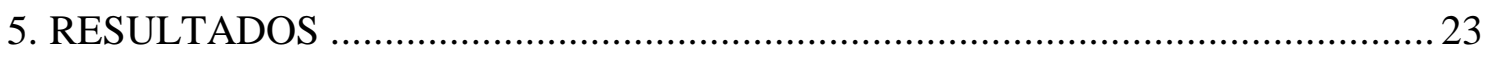

5.1 Perfil de usuario de los Servicios Sociales de Melilla..................................... 23

5.2 Estilo de vida según las características sociodemográficas y culturales. .............26

5.3 Patrón de consumo alimentario y grado de cumplimiento de las recomendaciones

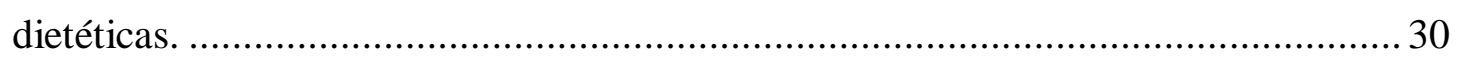

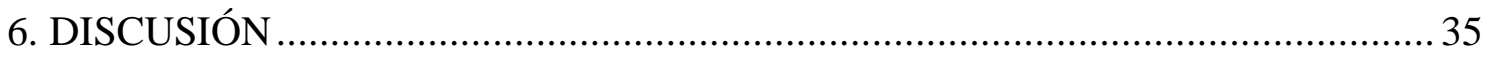

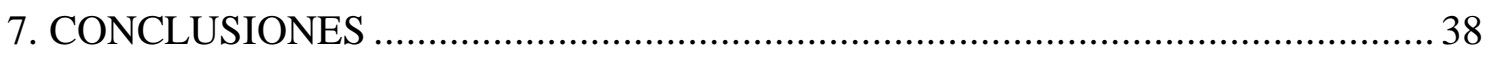

REFERENCIAS BIBLIOGRÁFICAS ......................................................... 40

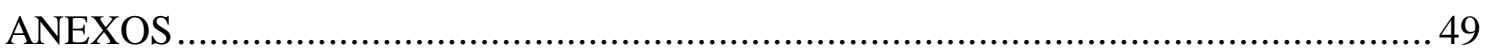




\section{ÍNDICE DE TABLAS}

Tabla 1. Variables sociodemográficas y culturales. ...................................................2 24

Tabla 2. Antecedentes y hábitos en salud. ............................................................ 27

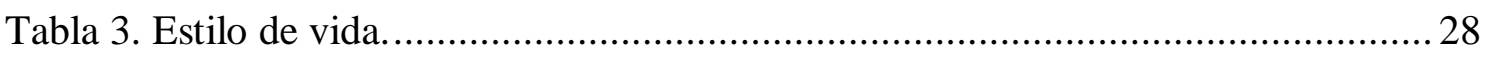

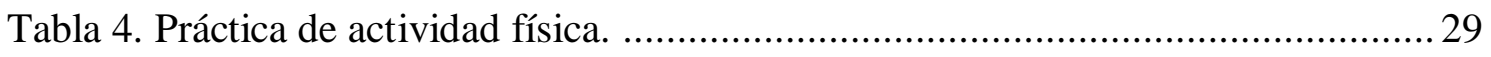

Tabla 5. Distribución de la ingesta diaria según el sexo......................................... 30

Tabla 6. Distribución de la ingesta diaria según la etnia............................................. 31

Tabla 7. Distribución de la ingesta diaria según la edad................................................ 32

Tabla 8. Evaluación nutricional del consumo de alimentos......................................... 33 


\section{ÍNDICE DE FIGURAS}

Figura 1. Tasa y umbral de riesgo de pobreza, 2017 ........................................... 6

Figura 2. Tasa de riesgo de pobreza por comunidades y ciudades autónomas ................ 6

Figura 3. Tasa de riesgo de pobreza y/o exclusión social por grupos de edad en España 7

Figura 4. Tasa de riesgo de pobreza y/o exclusión social por situación laboral en España

Figura 5. Tasa de riesgo de pobreza y/o exclusión social por nivel de educación en

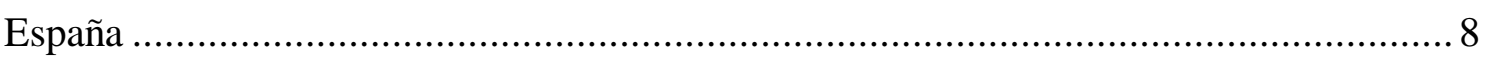

Figura 6. Tasa de desempleo en España de 2000 a 2019 .......................................... 10

Figura 7. Tasa de desempleo en los estados miembros de la UE en enero de $2020 \ldots . . .11$ Figura 8. Tasa de jóvenes entre 16 y 29 años en riesgo de pobreza o exclusión social en

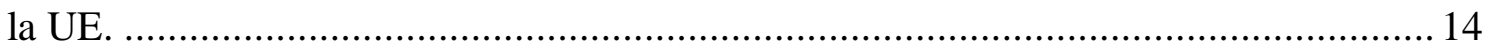

Figura 9. Principales colectivos en riesgo de exclusión social...................................... 16

Figura 10. Evolución de las puntuaciones del índice DEC a nivel general y para cada uno de sus apartados desde 2012 a 2018 18 


\section{INTRODUCCIÓN}

La crisis financiera del 2008 provocó una grave recesión en España que condujo a la adopción de medidas austeras entre las que se incluyeron recortes del gasto público, incremento de impuestos, y reformas del mercado laboral con el consiguiente aumento del desempleo y precarización laboral (Salom, 2019). Todas estas medidas contribuyeron a acentuar aún más las desigualdades sociales, causando un mayor costo en los estratos más vulnerables (San Juan, 2019) y un amplio sector de la clase obrera (Colectivo IOÉ, 2015).

Hasta ese momento, los pactos sociales habían constituido un elemento esencial en la determinación de políticas socioeconómicas y un refuerzo de "la legitimidad de la toma de decisiones públicas” (Begega \& Balbona, 2015). No obstante, la irrupción de la crisis suscitó el cambio de un modelo de pacto y negociación a uno de imposición, impulsado por la reorientación estratégica de gobierno y agentes sociales (Lima \& Artiles, 2011), que efectuaron recortes precisamente en un momento convulso y de mayor necesidad (Martín, Pericacho, \& Gómez, 2020), favoreciendo con ello un incremento de la tasa de pobreza y el número de individuos en riesgo de exclusión social (Salom, 2019).

Durante la crisis se han observado además, cambios en el patrón de consumo (Alonso, Rodríguez, \& Rojo, 2016) donde la privación alimentaria ha dificultado la satisfacción de demandas nutricionales e ingesta adecuada de alimentos, cuya selección no ha atendido a una lógica nutricional sino a criterios económicos que anteponen el precio a la calidad y rentabilizan al máximo los recursos disponibles (Díaz-Méndez, Estévez, \& Espejo, 2019).

Toda esta situación de desgaste y estancamiento económico aún presentes en la actualidad, han conducido a buena parte de la ciudadanía española a recurrir a las ayudas institucionales de modo que los Servicios Sociales han experimentado un aumento de la demanda, al mismo tiempo que han aparecido nuevos perfiles de usuarios con respecto al perfil clásico (Domínguez, 2017). 


\section{MARCO TEÓRICO}

\subsection{Origen de la crisis económica}

Desde 1994 hasta comienzos del 2008, el mundo experimentó una segunda época dorada: un largo periodo de prosperidad generalizada, rápido crecimiento económico y estabilidad de precios, observados en la mayoría de países con economías emergentes y en desarrollo, que presenciaron tasas de crecimiento elevadas que alcanzaron el $8.3 \%$ en 2007. Desafortunadamente, esos tiempos de prosperidad cesaron bruscamente en la segunda mitad de 2008 (Fernández-Villaverde \& Ohanian, 2010).

Pues como toda economía de mercado caracterizada por las fluctuaciones cíclicas, las fases expansivas se acompañaron de etapas recesivas generando una sucesión de desequilibrios como inflación y endeudamiento de agentes económicos, marcando así un periodo de declive que resultó en la declinación de la renta y paralización de actividades económicas entre otros efectos (Mir, 2009) .

Así, la recesión global fue fruto de la combinación de varios elementos de una tormenta económica perfecta (Fernández-Villaverde \& Ohanian, 2010) como la especulación de mercado efectuada por los bancos mundiales, la crisis del petróleo (por encarecimiento) originada por la OPEP (Organización de Países Exportadores de Petróleo) en 2008 (Staszczak, 2019) y el hundimiento de los activos hipotecarios ocasionado por la crisis inmobiliaria, que perjudicó a numerosos bancos de EE.UU y Europa contribuyendo en gran medida a la desaparición de la banca de inversión (Mir, 2009).

En España, según Mir (2009) "han coincidido dos crisis: la financiación mundial y la inmobiliaria española, con efectos acumulados en el deterioro de nuestra economía, ambas influidas por una excesiva dependencia de la financiación exterior" generando en el país un elevado coste social en materia de pobreza, desempleo y desigualdad, tres fenómenos estrechamente vinculados (San Juan, 2019) cuyas consecuencias han afectado mayormente a los estratos sociales más vulnerables y muy especialmente a quienes se hallan en situación de desempleo o no perciben prestaciones, y a un amplio sector de la clase media y trabajadora (Colectivo IOÉ, 2015).

La irrupción de la crisis, condujo a la adopción de medidas austeras que efectuaron recortes sociales en un momento dramático, convulso y de mayor necesidad 
(Martín et al., 2020), lo que provocó la desconfianza en las instituciones y un descontento social generalizado (San Juan, 2019); reacción justificada dado el resultado de la aplicación de tales medidas que causó una caída de los ingresos, imposibilidad de afrontar gastos y un incremento de la población en riesgo de pobreza y exclusión social (Colectivo IOÉ, 2015). Dicho resultado reflejaba según Martín et al.(2020) un fracaso estrepitoso del Estado de Bienestar, incapaz de proteger a sus ciudadanos en un momento en el que éstos requerían una "mayor altura de miras" a la cual los políticos no han sabido responder (FOESSA, 2016).

Y es que ,a partir de la crisis, se produjo un deterioro de los pactos sociales con la consiguiente transición de un modelo de pacto a uno de imposición (Lima \& Artiles, 2011), causando un desgaste de la lógica consensual de la que participaban gobiernos y agentes sociales, y que hasta ahora había garantizado la "legitimidad de la toma de decisiones públicas" al tiempo que marcaba el ritmo de las reformas (Begega \& Balbona, 2015). Como consecuencia de dicha transición, los mecanismos corporativistas implicados en la creación de políticas socioeconómicas se han vuelto inestables dada la amenaza generada por la "reorientación estratégica" de los gobiernos en respuesta a la crisis económica (Lima \& Artiles, 2011), y pérdida de influencia sindical (Begega \& Balbona, 2015).

\subsection{Nivel de pobreza}

La pobreza es un tema preocupante y de interés tanto social como institucional cuya medición se ve justificada por la necesidad de dar respuesta a un grave problema de la sociedad. Su cuantificación no solo se limita a aportar cifras, sino que además establece los motivos, de modo que la información obtenida permite el desarrollo de políticas socioeconómicas dirigidas a mitigar los efectos de esta lacra social. No obstante, existen dificultades a la hora de cuantificar la pobreza dado que es un fenómeno complejo influenciado por numerosos factores que puede ser analizado desde diferentes enfoques y presentar múltiples interpretaciones, haciendo que existan diversas maneras de definirla y por lo tanto diversas maneras de medirla (García-Carro \& Sánchez-Sellero, 2019).

Según tales enfoques se pueden diferenciar: pobreza objetiva, pobreza subjetiva o privación multidimensional. La pobreza objetiva es aquella que basa su medición en la observación directa y variables objetivas como la renta y el gasto de los hogares. 
Dicha pobreza puede ser absoluta o relativa. La primera alude a circunstancias en las que no se satisfacen las necesidades básicas (habitualmente vinculadas a la alimentación, vestimenta y vivienda), mientras la segunda hace referencia a situaciones de desventaja social y económica de los individuos con respecto a la sociedad; pues dicha noción de pobreza está muy asociada al concepto de desigualdad. Siguiendo este criterio, la denominación $<<$ pobre $>>$ y $<<$ no pobre $>>$ se realizará en base al nivel de desarrollo de la sociedad objeto de estudio y no podrá ser extrapolada a otras sociedades distintas (INE, s.f.).

Por otro lado, la pobreza subjetiva asume que las personas son quienes mejor pueden juzgar su condición de pobreza (García-Carro \& Sánchez-Sellero, 2019), cuyo análisis atiende a la percepción y opinión personal de los individuos sobre su posición económica al contrario que el enfoque objetivo basado únicamente en variables observables y medibles

En último lugar, el término <<privación multidimensional〉> está muy ligado a la exclusión social y relacionado con la inaccesibilidad a determinados bienes y servicios, que siendo o no de primera necesidad son considerados básicos por la sociedad. Su cuantificación se efectúa mediante indicadores de privación y variables no monetarias.

Cualquiera de estas formas de entender y medir la pobreza, proporciona un enfoque distinto que aporta información diversa y valiosa, la cual ha de combinarse para lograr una perspectiva general lo más exhaustiva posible.

Las medidas oficiales se fundamentan en la Encuesta de Condiciones de Vida (ECV), que cumplen las recomendaciones metodológicas del EUROSTAT (Oficina Europea de Estadísticas), el cual calcula al mismo tiempo los indicadores de pobreza para todos los estados miembros de la Unión Europea (UE) a partir de los datos aportados por la EU-SILC (Statistics on Income and Living Conditions). Así, tales medidas obtenidas de la ECV, permiten proporcionar datos altamente comparables en la UE al basarse en criterios armonizados, dotando a la Comisión Europea de una herramienta estadística importante para el análisis de la pobreza y la desigualdad, la determinación de necesidades de la población, las repercusiones de las políticas socioeconómicas sobre los individuos y los hogares, así como el diseño de nuevas estrategias (INE, s.f.). 
Según la Estrategia Europa 2020 (2010) se dice que una persona está en riesgo de pobreza y/o exclusión social cuando se halla en alguna de las tres circunstancias que se describen a continuación: aquéllas cuyos ingresos por unidad de consumo (correspondientes al año anterior al de la entrevista) están por debajo del $60 \%$ de la renta mediana disponible equivalente (después de transferencias sociales), personas de 0 a 59 años que pertenecen a hogares de baja intensidad laboral (inferior al 20\% de su potencial de trabajo total durante el año anterior a la entrevista), y personas que sufren una carencia material severa y presentan al menos 4 de los 9 elementos de privación siguientes: No pueden 1) pagar el alquiler o las facturas de servicios públicos, 2) mantener el hogar a una temperatura adecuada, 3) enfrentar gastos inesperados, 4) comer carne, pescado o un equivalente de proteína cada dos días, 5) una semana de vacaciones fuera de casa, 6) un automóvil, 7) una lavadora, 8) un televisor a color, 9) un teléfono.

En 2017 (año al que corresponden las últimas estadísticas disponibles), la Unión Europea experimentó una disminución del riesgo de pobreza del 16,9\%. Asimismo, la tasa calculada para los 28 estados miembros de la Unión Europea (ver Figura 1), mostró que en nueve de ellos incluida España (21,6 \%), al menos una quinta parte de la población se hallaba en riesgo de pobreza. Por otro lado, Rumanía fue el estado con mayor umbral de pobreza $(23,6 \%)$ mientras República Checa $(9,1 \%)$ presentó la menor tasa de pobreza. 


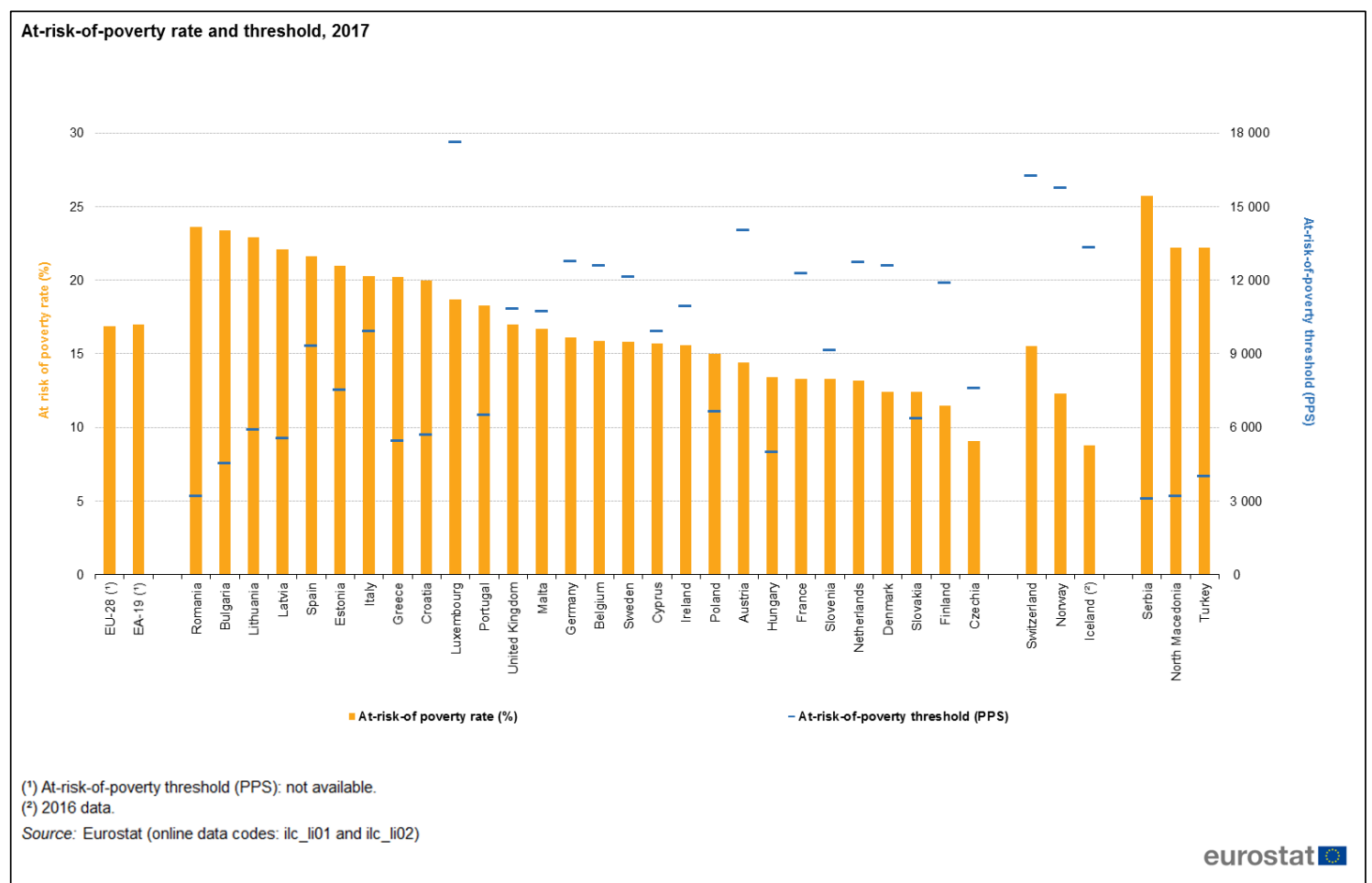

Figura 1. Tasa y umbral de riesgo de pobreza, 2017. (Fuente: EUROSTAT, 2019).

En España en 2018 (últimos datos disponibles) la media nacional reflejó una tasa de riesgo de pobreza del 21, 5\% (ver Figura 2). Ceuta fue la ciudad autónoma con la mayor tasa de pobreza $(38,3 \%)$ y el País Vasco, la comunidad autónoma que obtuvo el menor porcentaje $(8,6 \%)$.

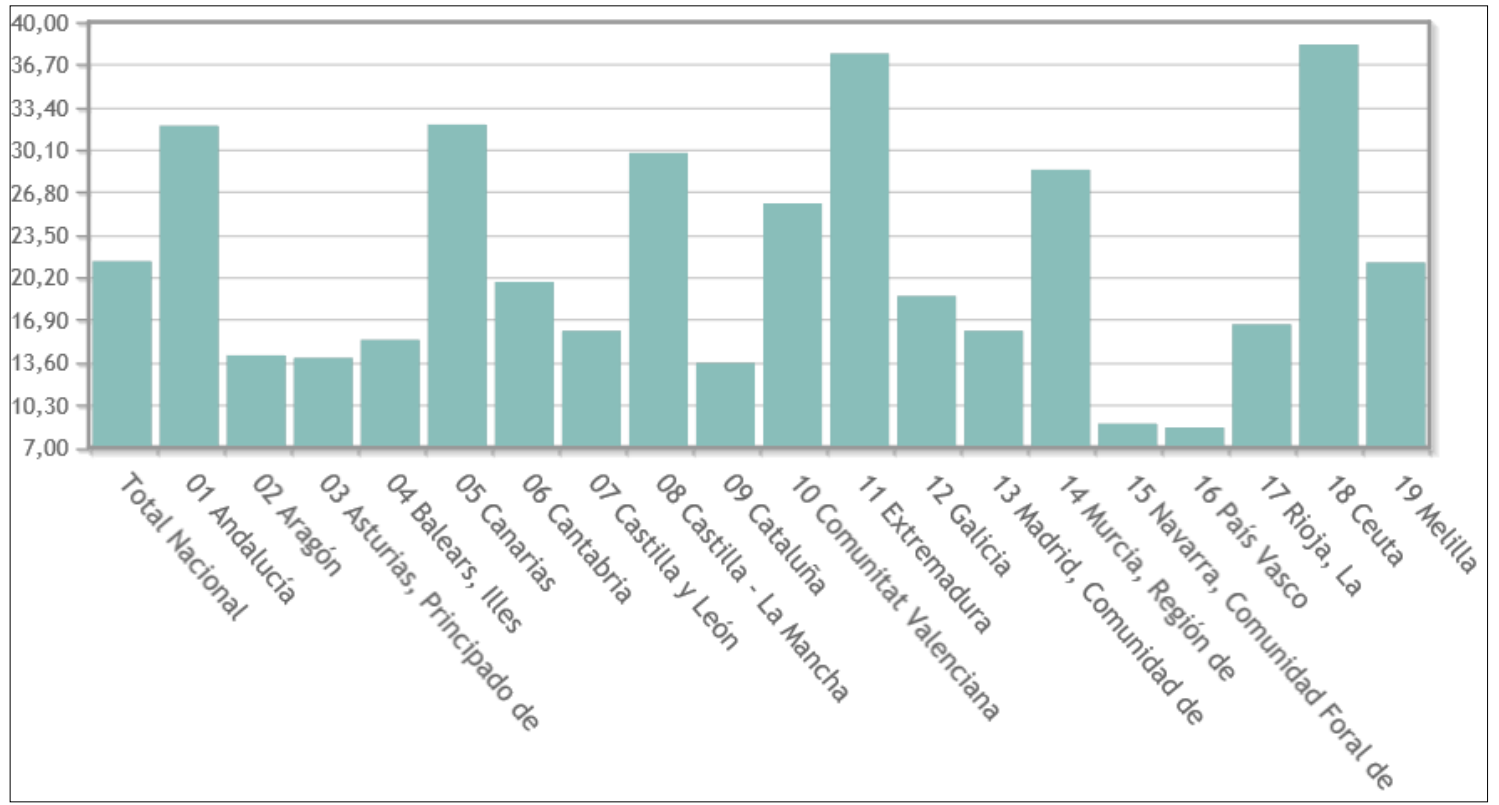

Figura 2. Tasa de riesgo de pobreza por comunidades y ciudades autónomas. (Fuente: ECV, 2018). 
Atendiendo al género, los resultados mostraron que el $27 \%$ de los hombres cumplían alguna de las tres condiciones de riesgo de pobreza o exclusión social frente al $25,1 \%$ de mujeres.

Por grupos de edad (ver Figura 3), el mayor porcentaje en mujeres correspondió a jóvenes de 16 a 29 años representando un 30,5\%, mientras que el menor porcentaje pertenecía a mujeres de 65 años o más, cuyo valor fue del 16,3\%. En el caso de los hombres, el mayor porcentaje también lo ocupaban jóvenes de 16 a 29 años con el $37,2 \%$, y el porcentaje más bajo lo ocuparon los mayores de 65 años o más, cuya cifra fue del $18,7 \%$.

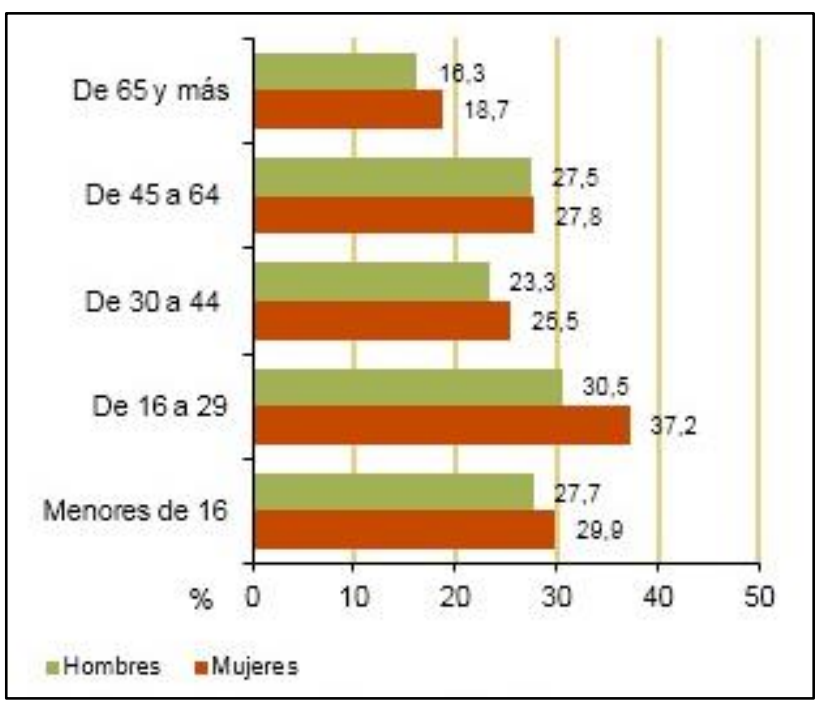

Figura 3. Tasa de riesgo de pobreza y/o exclusión social por grupos de edad en España. (Fuente: ECV, 2018).

Según la situación laboral (ver Figura 4), los parados fueron quienes presentaron el mayor porcentaje de riesgo de pobreza o exclusión social, siendo más alto en hombres $(72,4 \%)$ que en mujeres $(59,3 \%)$. 


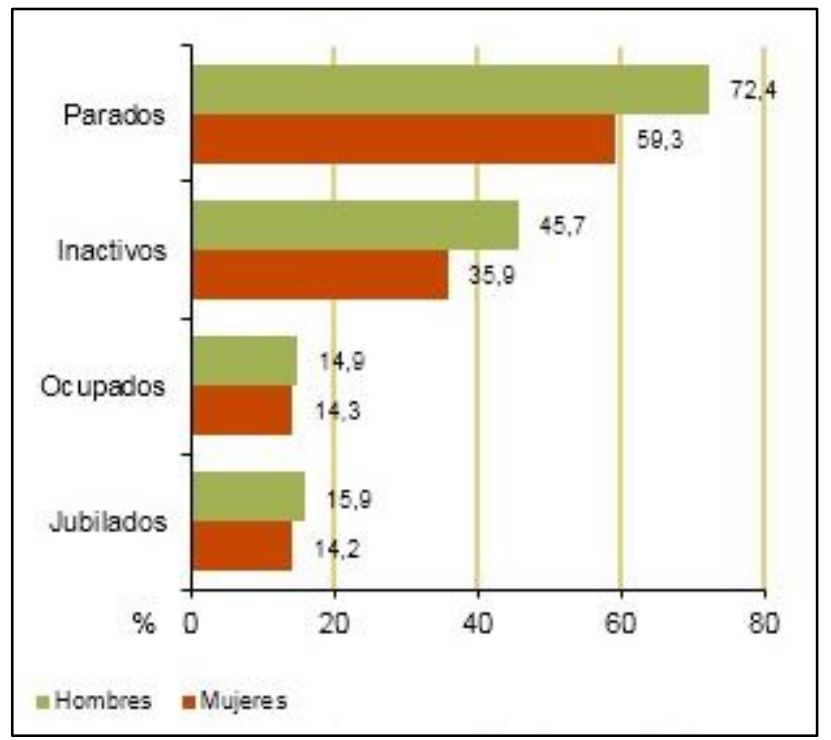

Figura 4. Tasa de riesgo de pobreza y/o exclusión social por situación laboral en España. (Fuente: EUSILC, 2018).

Por último, según el nivel educativo (ver Figura 5), se obtuvieron tasas de riesgo de pobreza o exclusión social mayores en personas con los niveles más inferiores (0-2), siendo ligeramente más alto en mujeres $(33,8 \%)$ que en hombres $(33,2 \%)$. Se observó que dichos porcentajes disminuían a medida que aumentaba el nivel educativo.

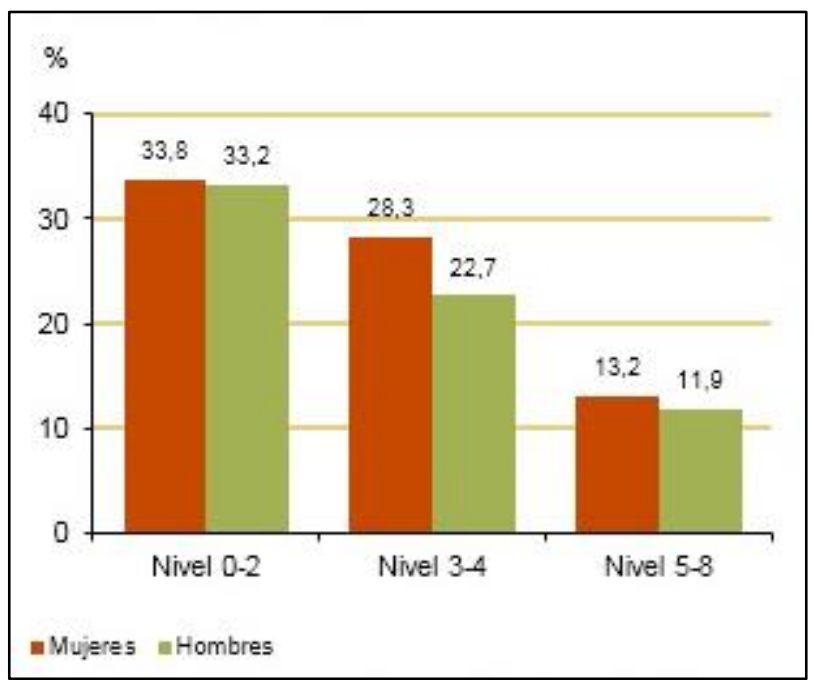

Figura 5. Tasa de riesgo de pobreza y/o exclusión social por nivel de educación en España. (Fuente: EUSILC, 2018).

En conclusión, podemos afirmar que el género, la edad, la situación laboral, y el nivel educativo son condicionantes de pobreza. 


\subsection{Las desigualdades sociales}

Durante las últimas décadas en España, se ha evidenciado el carácter anticíclico de la pobreza y la exclusión social. Frente a épocas de recesión económica, se ha observado un rápido incremento de la pobreza, mientras que, en épocas de crecimiento ésta no ha disminuido en la misma medida y permanece estancada (FOESSA, 2016). El VII Informe FOESSA (2014) sobre exclusión y desarrollo social en España reflejó la no imparcialidad de la crisis: ésta no estaba generando el mismo impacto en todos.

Por otra parte, cuando se habla de regeneración económica, disminución de la tasa de desempleo, mejoramiento del crecimiento etc., no se presta atención al hecho de que las consecuencias de la crisis no otorgan a todo el mundo la posibilidad de salir de la situación económica desfavorable (resultante de dicha recesión) a pesar de vivir un nuevo ciclo económico favorable. Pues las secuelas y efectos de la recesión se han vivido de manera distinta en los hogares y a nivel individual, así como en las diferentes regiones de nuestro país (FOESSA, 2016).

Para determinar la desigualdad presente en una sociedad se utiliza como punto de referencia el grado de desigualdad que dicha sociedad considera aceptable. El nivel de desigualdad tolerable irá en función de las preferencias sociales, y la distribución específica de la renta; es decir, si la desigualdad en la distribución de la renta es originada por una polarización de la riqueza en una minoría privilegiada, o si dicha desigualdad es a causa del empobrecimiento de las rentas más bajas. Por otra parte, es necesario considerar los indicadores de pobreza absoluta y la evolución de los niveles de renta: un incremento de la desigualdad puede ser más aceptable en un marco de crecimiento generalizado que en un contexto recesivo. E igualmente importante será describir las causas de la desigualdad. Las posturas más progresistas subrayan la equidad en los resultados, mientras que las más liberales defienden la disminución de la desigualdad de oportunidades sin prestar atención a la disparidad de los resultados (San Juan, 2019).

Una investigación reciente sobre estimación de <<desigualdad injusta〉> (Hufe, Kanbur, \& Peichl, 2018), revela que en Europa, Lituania es el país con la tasa más alta (31.6\%) mientras que Holanda representa el porcentaje más bajo (7\%). En el caso de España, el nivel de desigualdad injusta alcanza el 25\%, muy superior al promedio europeo. 
En relación a los efectos de la crisis, el más notable ha sido el desempleo (San Juan, 2019), el cual aumentó considerablemente en el año 2008 al mismo tiempo que se producían reformas laborales que favorecían la precarización promovida por la flexibilización característica del mercado de trabajo -agudizada en tiempo de crisis-, que brindaba peores contratos y salarios, y que dado el abaratamiento de los despidos, limitaba el poder de negociación de los empleados con sus empleadores (MartínezMartín, García-Moreno, \& Lozano-Martín, 2018). Aunque, a partir de 2014 (Ver figura 6), los niveles de desempleo se han ido reduciendo y el país ha experimentado una recuperación paulatina. No obstante, pese a la fuerte caída del desempleo, España continúa siendo el segundo estado miembro de la UE con la mayor tasa de paro (ver figura 7), lo que intensifica las desigualdades y aumenta la pobreza.

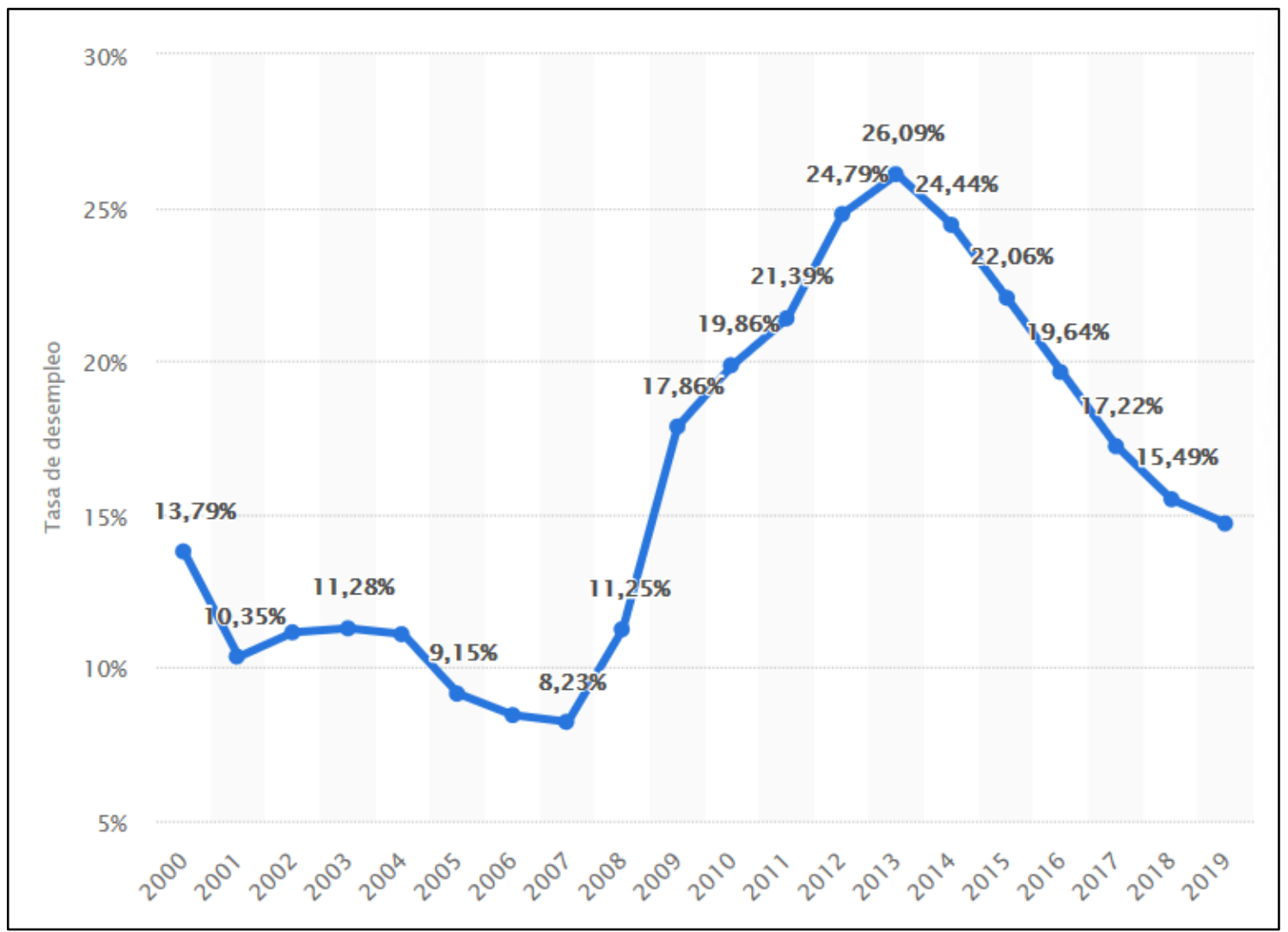

Figura 6. Tasa de desempleo en España de 2000 a 2019. (Fuente: EUROSTAT, 2020). 


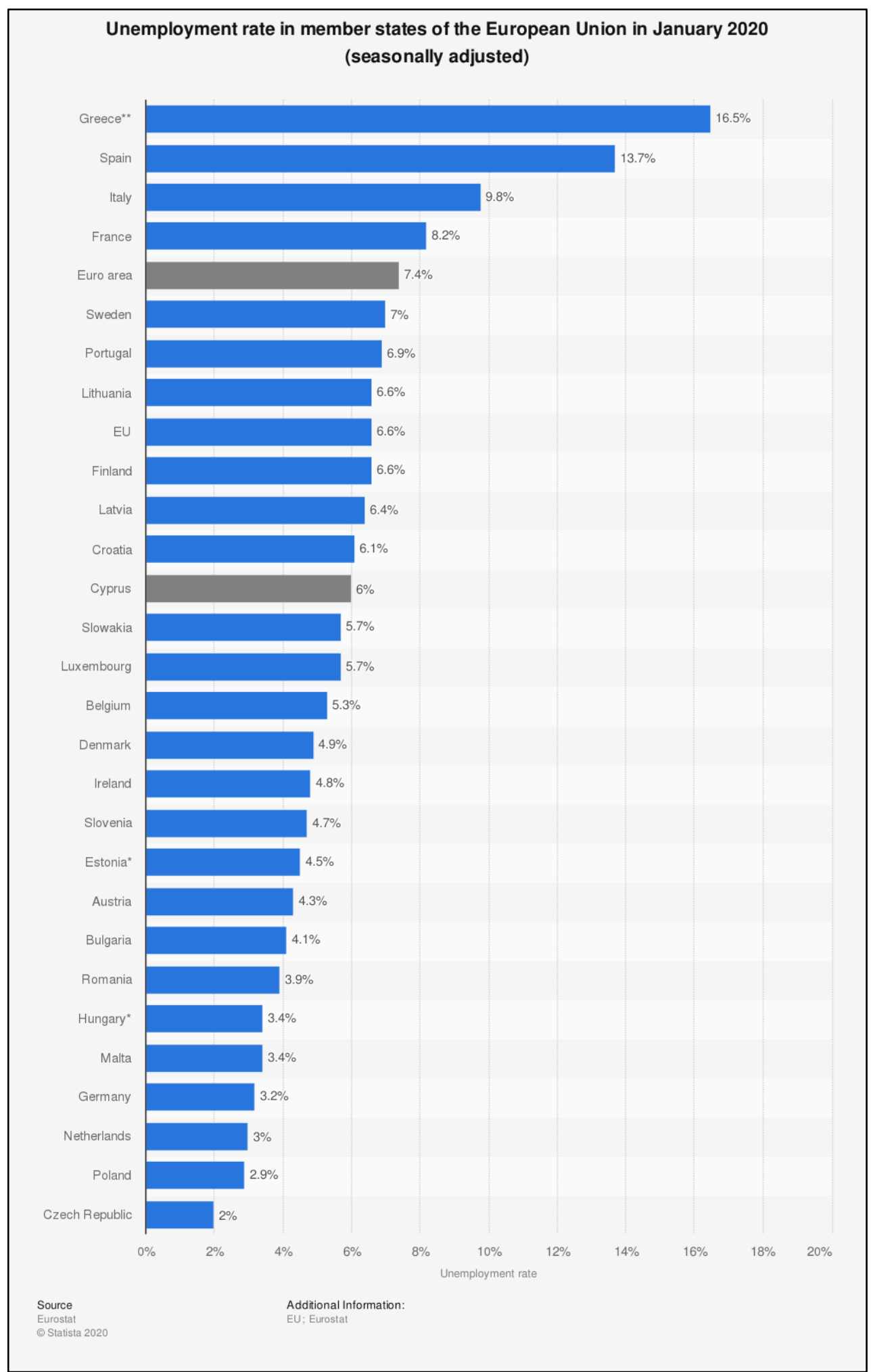

Figura 7. Tasa de desempleo en los estados miembros de la UE en enero de 2020. (Fuente: EUROSTAT, 2020).

Según la Organización para la Cooperación y el Desarrollo Económico (OCDE, 2018) el mercado laboral sigue muy segmentado y registra un elevado índice de contratos temporales y altas tasas de paro de larga duración y desempleo juvenil. 
Los jóvenes han sido víctimas de la brecha generacional originada durante la crisis, constituyendo el grupo de edad que mayormente ha sufrido sus consecuencias (Eraso, Icart, Matu, \& Pastor, 2011; Marí-klose, 2019; San Juan, 2019). En este sentido, Chen et al., (2018) exponen que el incremento de la desigualdad entre jóvenes y mayores se da de manera generalizada en la UE, y pronostican que, si estos jóvenes no consiguen ser incorporados en el mercado laboral bajo unas condiciones adecuadas ni se les ofrecen garantías de progreso durante su trayectoria profesional, buena parte de ellos tendrá una perspectiva de futuro desalentadora, donde se perciban como futuros empleados ocupando puestos de trabajo poco cualificados, temporales y mal remunerados. A estas pesimistas expectativas de trabajo y poco prometedoras, se suma la percepción de un futuro con mayores impuestos, más años de cotización y prestaciones más bajas, tan pronto como el envejecimiento de la población amenace el estado de bienestar.

Concretamente en España, los jóvenes activos no alcanzan la tercera parte de los trabajadores de mediana edad, un resultado mucho más negativo que la media de la OCDE. Además, a esta desigualdad intergeneracional en el ámbito laboral, hay que sumar otras como la desigualdad de oportunidades originadas por bajo nivel educativo; pues se observa que las personas que poseen un bajo nivel de estudios, tienen un $15 \%$ menos de probabilidades de obtener empleo que aquéllas con estudios superiores, lo que refleja en nuestro país una brecha mayor a la presente en dos tercios de la OCDE (OCDE, 2018).

Otro grupo afectado por la vulnerabilidad laboral ha sido el de los extranjeros, quienes han tenido más dificultades para afrontar la crisis con unos niveles de desempleo superiores a la media, sueldos más bajos y mayor riesgo de pobreza. En referencia a lo anterior, Carpio (2015) expone que se puede afirmar que existe una mayor vulnerabilidad laboral en la población extranjera que en la española; si bien según éste, convendría definir las posibles causas, para lo cual propone analizar cinco razones que pueden ayudar a determinar dichas causas: estar peor situado en la escala ocupacional, la abundancia de contrataciones temporales, trabajar casi exclusivamente en el sector de la construcción, la inflexibilidad normativa, y la disminución del poder de negociación de los españoles (la crisis ha hecho que los empleos rechazados por muchos españoles se convirtieran en objetivo para los extranjeros). 
Otro efecto de la crisis, ha sido el incremento significativo de la desigualdad en la distribución de la renta, que crecía a medida que se producía una disminución considerable del empleo y aumentaba la disparidad de ingresos. Asimismo, se aprecian desigualdades en la distribución de la riqueza: aproximadamente el 50\% de la riqueza total se concentra en el $10 \%$ de los hogares más pudientes, mientras que cerca del $20 \%$ de la riqueza está distribuida entre el $60 \%$ de la población más pobre. Además, puesto que la acumulación de la riqueza necesita tiempo, el aumento reciente de la desigualdad de los ingresos y las actuales tendencias del mercado laboral, pueden generar a largo plazo una concentración de la riqueza aún superior (OCDE, 2018).

En relación a lo anterior, la situación de los extranjeros resulta muy peculiar, pues el nivel de renta anual por persona es muy inferior al de los españoles y nunca ha sobrepasado los $9.000 €$, mientras que en el segundo caso supera los $11.000 €$; y otro aspecto llamativo, es el comportamiento de dicha renta que ha variado en función de la procedencia de los extranjeros según eran de la UE o del resto del mundo, siendo inferior en el segundo caso. Estos datos exponen una clara desigualdad en la distribución de la renta asociada a la nacionalidad, que unido a la caída de tal renta (entre españoles y extranjeros) refleja una brecha estructural evidente en la sociedad española (Martínez-Martín et al., 2018).

Además de las desigualdades descritas anteriormente, cabría destacar el incremento de la pobreza, especialmente de la población infantil, cuya cifra es considerablemente más alta que el promedio de la OCDE; y se observa, que el riesgo es notablemente elevado en niños que pertenecen a familias monoparentales y migrantes. Por otro lado, el $80 \%$ de niños pobres en edad escolar presentan carencias materiales en diferentes espacios, incluidos el hogar y el ámbito educativo. A este respecto, la OCDE (2018) expone que "abordar los altos índices de privación material requerirá de la acción coordinada y conjunta en las políticas de salud, educación y vivienda". Igualmente, manifiesta que las políticas de empleo destinadas a propiciar las condiciones óptimas para que los padres obtengan trabajo, resultarían decisivas para combatir la pobreza infantil, dado que ésta, está muy vinculada a la mala situación laboral de los mismos; y plantea el desarrollo de servicios extraescolares asequibles que ayuden a los padres a preservar su trabajo. 
Otro grupo especialmente vulnerable ha sido el de los jóvenes. España es el cuarto país miembro de la UE con la mayor tasa de jóvenes entre 16 y 29 años en riesgo de pobreza o exclusión social, cuyo porcentaje es del 33,8\% (Ver figura 8).

\begin{tabular}{|c|c|c|c|}
\hline \multicolumn{4}{|c|}{$\begin{array}{l}\text { Share of young people (aged 16-29 years) at risk of poverty or social exclusion, } 2018 \\
(\%)\end{array}$} \\
\hline & Total & Young men & Young women \\
\hline EU-28 & 26.3 & 25.2 & 27.4 \\
\hline Belgium & 21.9 & 20.8 & 22.9 \\
\hline Bulgaria & 32.7 & 34.4 & 30.9 \\
\hline Czechia & 11.6 & 10.2 & 13.1 \\
\hline Denmark & 37.3 & 35.0 & 38.9 \\
\hline $\begin{array}{l}\text { Germany } \\
\text { Estonia }\end{array}$ & 24.2 & 22.0 & 26.5 \\
\hline $\begin{array}{l}\text { Estonia } \\
\text { Ireland }\end{array}$ & 20.2 & 20.4 & 20.0 \\
\hline $\begin{array}{l}\text { Ireland } \\
\text { Greece }\end{array}$ & 21.9 & $\begin{array}{l}21.5 \\
402\end{array}$ & 22.4 \\
\hline $\begin{array}{l}\text { Greece } \\
\text { Spain }\end{array}$ & $\begin{array}{l}40.2 \\
33.8\end{array}$ & $\begin{array}{l}40.2 \\
30.5\end{array}$ & $\begin{array}{l}40.2 \\
37.2\end{array}$ \\
\hline France & 21.8 & 22.9 & 20.7 \\
\hline Croatia & 20.6 & 20.1 & 21.1 \\
\hline Italy & 33.6 & 31.8 & 35.4 \\
\hline Cyprus & 26.3 & 26.5 & 26.1 \\
\hline Latvia & 22.1 & 22.5 & 21.6 \\
\hline Lithuania & 24.5 & 23.6 & 25.4 \\
\hline Luxembourg & 27.5 & 28.1 & 26.9 \\
\hline Hungary & 22.2 & 19.7 & 24.8 \\
\hline Malta & 13.1 & 14.5 & 11.7 \\
\hline Netherlands & 24.8 & 23.5 & 26.1 \\
\hline Austria & 20.3 & 18.8 & 21.9 \\
\hline Poland & 20.9 & 20.6 & 21.1 \\
\hline Portugal & 24.1 & 25.4 & 22.8 \\
\hline Romania & 35.3 & 33.8 & 37.0 \\
\hline Slovenia & 14.7 & 14.0 & 15.4 \\
\hline Slovakia & 17.0 & 15.5 & 18.7 \\
\hline Finland & 25.3 & 25.0 & 25.6 \\
\hline $\begin{array}{l}\text { Sweden } \\
\text { United Kingdom }\end{array}$ & 27.0 & 27.5 & 26.5 \\
\hline$\frac{\text { United Kingdom }}{\text { Iceland (") }}$ & $\frac{26.6}{157}$ & $\frac{25.1}{14.9}$ & 28.2 \\
\hline $\begin{array}{l}\text { Iceland (") } \\
\text { Norway }\end{array}$ & $\begin{array}{l}15.7 \\
340\end{array}$ & $\begin{array}{l}14.9 \\
355\end{array}$ & $\begin{array}{l}16.6 \\
3.5\end{array}$ \\
\hline $\begin{array}{l}\text { Norway } \\
\text { Switzerland }\end{array}$ & 34.0 & 35.5 & 32.5 \\
\hline $\begin{array}{l}\text { SWitzenlana } \\
\text { North Macedonia }\end{array}$ & $\frac{16.4}{44.4}$ & $\frac{17.5}{45.5}$ & $\frac{15.2}{43.2}$ \\
\hline Serbia & $\begin{array}{l}44.4 \\
35.7\end{array}$ & $\begin{array}{l}45.5 \\
36.5\end{array}$ & $\begin{array}{l}43.2 \\
34.7\end{array}$ \\
\hline Turkey $(2)$ & 42.4 & 41.0 & 42.9 \\
\hline \multirow{2}{*}{\multicolumn{4}{|c|}{$\begin{array}{l}\text { (') } 2016 . \\
\text { (2) } 2017 .\end{array}$}} \\
\hline & & & \\
\hline \multicolumn{4}{|c|}{ Source: Eurostat (online data code: ilc_peps01) } \\
\hline & & & eurc \\
\hline
\end{tabular}

Figura 8. Tasa de jóvenes entre 16 y 29 años en riesgo de pobreza o exclusión social en la UE. (Fuente: EUROSTAT, 2018).

Según Marí-klose (2019) "los mayores costes sociales de la crisis en Europa" han afectado principalmente a la juventud, que ha tenido dificultades de acceso al mercado laboral y ha visto paralizada su emancipación y por ende su transición a la vida adulta. Pues éstos, habían mantenido la esperanza de que una vez llegaran a la adultez, ocuparían las posiciones privilegiadas que la sociedad reservaba a los adultos. Sin embargo, se sienten abrumados por la incertidumbre y la indeterminación y mantienen muy bajas expectativas de futuro. Asimismo, Marí-klose manifiesta que existe una necesidad apremiante de dar respuestas a esta situación dramática, y que es el sistema de protección social donde han de plantearse tales respuestas; y añade, que urge restituir la justicia intergeneracional y destinar medidas y recursos encaminados a favorecer el 
desarrollo pleno de los jóvenes para combatir la pobreza juvenil, y contribuir con ello a un Estado de Bienestar más igualitario.

\subsection{El Estado de Bienestar y los Servicios Sociales}

La constitución y el refuerzo del Estado de Bienestar, ha supuesto uno de los grandes logros de los países europeos en la lucha contra las desigualdades, y surge como resultado de la voluntad de las comunidades de proporcionar una vida digna a sus ciudadanos. Su creación tras la Segunda Guerra Mundial supuso un gran avance histórico, e implicó la instauración de una estructura institucional de carácter público fundamentada en los principios de una educación, sanidad y Servicios Sociales, gratuitos y universales, que fue posible gracias a las políticas redistributivas y solidaridad de la ciudadanía, fundamentales para alcanzar la cohesión social. Sin embargo, la irrupción de la crisis en 2008 ha generado desequilibrios en el Estado de Bienestar y sus principios: durante los últimos años las políticas económicas se han centrado en disminuir la deuda y el déficit público a expensas de la reducción del gasto público, y mediante la adopción de medidas austeras propias de los modelos neoliberales y muy contrarias a las políticas sociales; estas medidas se han instaurado en un momento de gran necesidad, ignorando las demandas de la sociedad y sumiendo a buena parte de la población en una crisis sin precedentes, lo que ha puesto en cuestionamiento tales políticas sociales (García \& Cabello, 2015).

El caso de España es particularmente llamativo. Se adhirió al Estado de Bienestar tardíamente -después de cuatro decenios de dictadura- y consiguió desarrollar un sistema de protección social durante los años 80 y 90 que lo aproximaron a sus compatriotas europeos; no obstante, este hecho resultaba paradójico dado que en ese momento la crisis del Estado de Bienestar ya era una realidad inminente: en los años anteriores a la crisis (1985-2000) España protagonizaba una escena poco convencional al lograr reducir las desigualdades en la renta disponible del hogar familiar y en la renta neta de trabajo (Stiglitz, 2012); sin embargo, ese equilibrio se vería alterado con la llegada de la crisis, afectando de manera muy intensa a nuestro país y otros países del sur de Europa, los cuales habían seguido un modelo de desarrollo económico a corto plazo basado en la creación de empleos poco cualificados, inestables, y débiles frente a épocas de recesión, lo que repercutía directamente sobre el sistema de protección social (Gilsanz, 2014). 
De entre los pilares del Estado de Bienestar, el sistema de Servicios Sociales ha sido el más inconcreto, frágil y expuesto a los cambios estructurales y coyunturales, creándose consecuentemente una necesidad de replanteamiento constante. Aunque, dado el contexto actual de vulnerabilidad, neoliberalismo y crisis social, cobra un significado transcendental y es más imprescindible que nunca para proteger a los colectivos más vulnerables (Ver figura 9) y prevenir su exclusión social. Pero desafortunadamente, a pesar de la voluntad y el esfuerzo realizado para armonizarse con el resto de países del entorno, los Servicios Sociales de España se hallan en un proceso de deterioro determinado por una "descentralización imperfecta" y una financiación escasa y "descomprometida", que ponen en riesgo la universalidad de los derechos y el acceso igualitario, y comprometen la capacidad de asistencia de dichos servicios (Gómez, 2012).

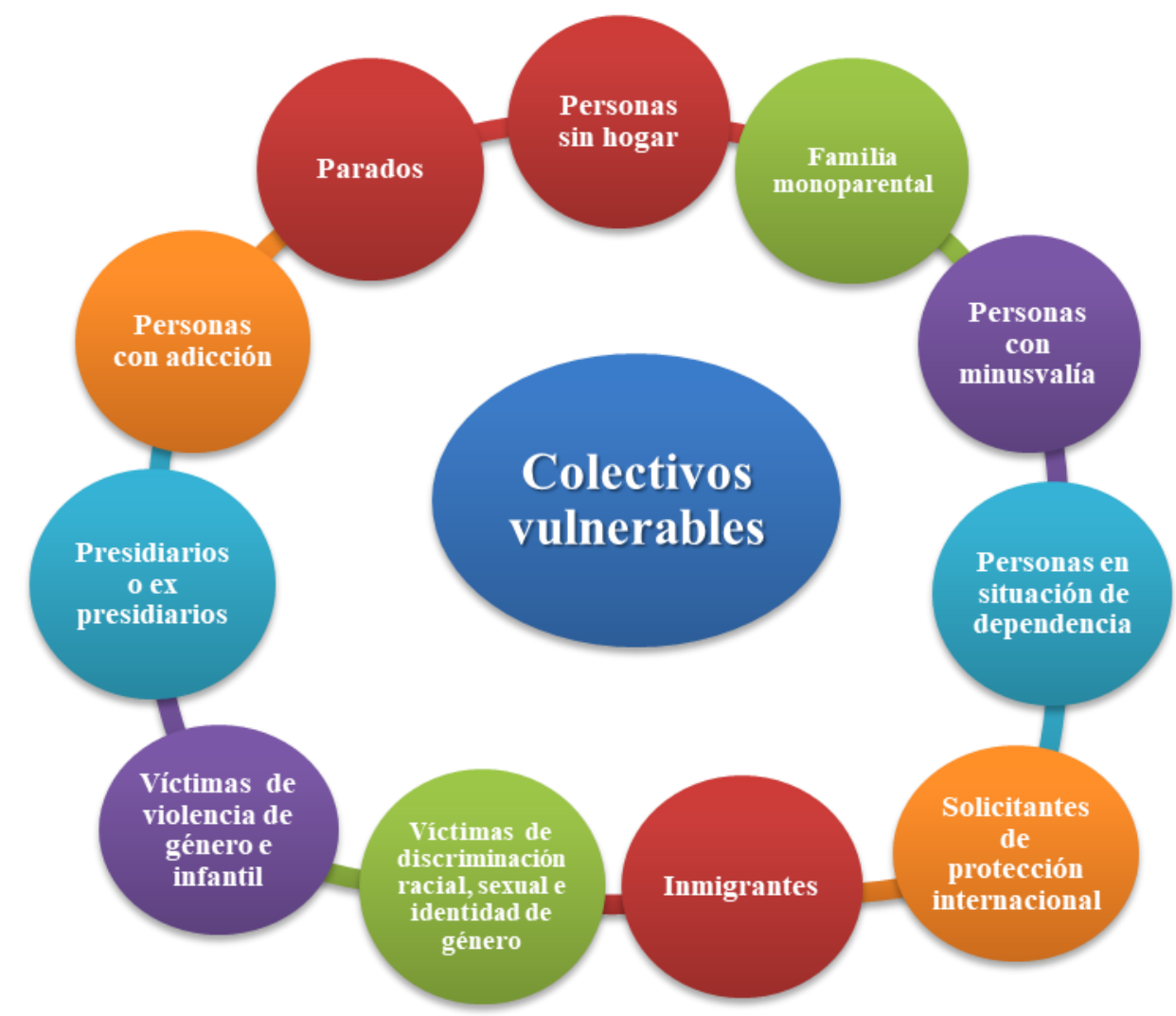

Figura 9. Principales colectivos en riesgo de exclusión social. (Fuente: Elaboración propia a partir de Afonso \& Sastre, 2017).

Las ayudas que brindan los Servicios Sociales, se clasifican en prestación de servicios y prestación económica. La primera, está encaminada a atender necesidades sociales y promover la inclusión social desde diferentes ejes temáticos como: la información y el asesoramiento; ayuda a domicilio y autonomía personal; mediación familiar; protección de menores; alojamiento alternativo; protección jurídica; y 
prevención e inserción social. La segunda, consiste en una aportación económica destinada a asegurar la cobertura de necesidades básicas y resolver situaciones de emergencia; como ejemplo podemos citar la renta mínima de inserción y las ayudas económicas para personas en situación de dependencia, entre otras (MSCBS, 2019).

$\mathrm{Si}$ bien estas prestaciones son comunes en todo el territorio español, las diferencias interregionales ponen de manifiesto su gran heterogeneidad (SIIS Centro de Documentación y Estudios, 2016). Y es que, a pesar de que la disparidad entre autonomías se ha reducido en los últimos años, ésta sigue siendo acusada. Dicha disparidad, viene determinada por el gasto dedicado a los Servicios Sociales por parte de gobiernos locales y autonómicos, el desarrollo normativo, y la cobertura real de dichos servicios; estos tres parámetros conforman el índice DEC (Derecho-EconomíaCobertura), utilizado para evaluar la evolución del Sistema Público de Servicios Sociales. A nivel nacional, la aplicación de dicho índice en 2018 (últimos datos disponibles) mostró un incremento con respecto al año anterior, alcanzando una puntuación total de 5,22 sobre 10 que fue la más elevada desde su primera aplicación en 2012 (Ver figura 10). Sin embargo, tal incremento supuso solo15 décimas con respecto al 2017, lo que refleja el estancamiento de los Servicios Sociales, que no evolucionan significativamente en cuanto a cobertura de necesidades se refiere. 


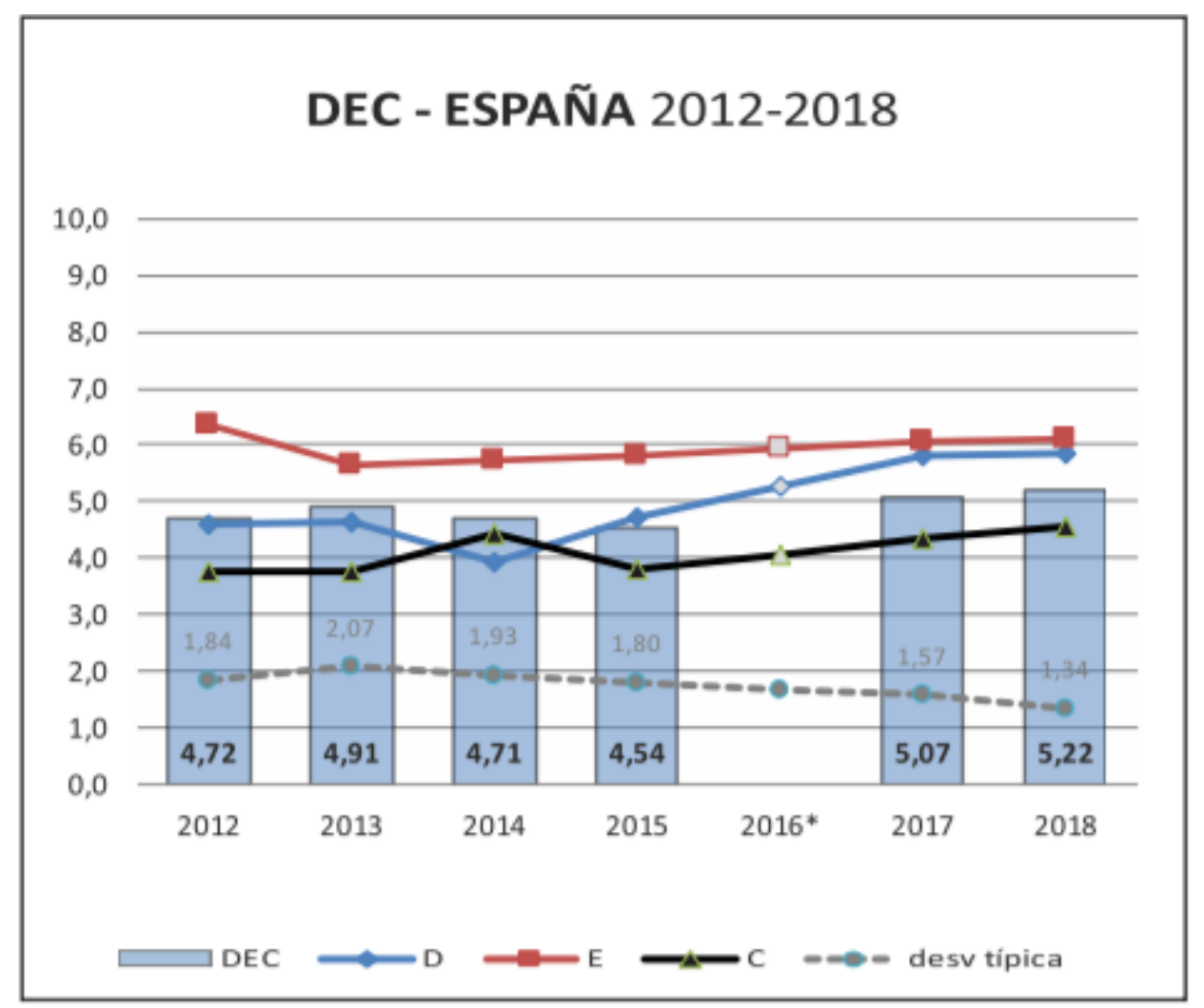

Figura 10. Evolución de las puntuaciones del índice DEC a nivel general y para cada uno de sus apartados desde 2012 a 2018. (Fuente: Asociación Estatal de Directores y Gerentes en Servicios Sociales, 2018).

Seis, fueron las propuestas generales sugeridas por el informe para mejorar la gestión y asistencia de los Servicios Sociales: reconocimiento constitucional del derecho a los Servicios Sociales, creación de una ley estatal en dicha materia, aprobación de una ley estatal de garantía de rentas, vertebración territorial, cumplimiento del pacto de Estado por la Dependencia y reforma del sistema estatal de información de Servicios Sociales (Asociación Estatal de Directores y Gerentes en Servicios Sociales, 2018).

Por otra parte, además de la desigualdad interregional mencionada anteriormente, existe desigualdad en el acceso a los Servicios Sociales. Durante la crisis, se ha observado una menor participación y consideración de los jóvenes en las políticas sociales (Peláez \& Sánchez-Cabezudo, 2015). Según Marí-klose (2019) los jóvenes han sido el grupo de edad que mayormente ha sufrido los costes sociales de la crisis, y responsabiliza de ello al Estado de Bienestar, el cual había contado hasta el momento con un sistema de protección social focalizado exclusivamente en la 
población de edad avanzada, por lo que plantea la necesidad de restituir la justicia intergeneracional para contribuir a un Estado de Bienestar más igualitario.

\subsection{El perfil de los usuarios de Servicios Sociales}

Cuando se produjo la Gran Recesión de 2008, los gobiernos occidentales ya estaban sumidos en una intensa crisis política y democrática que implicó además una crisis social promovida por el individualismo, la insolidaridad, y la apatía política; presentes incluso en años previos a la crisis, y los cuales no solo imperaban en la sociedad española sino en las democracias más avanzadas internacionalmente (Morán \& Benedicto, 2016; Porta et al., 2017).

En ese contexto, los Servicios Sociales han sido claves para suplir parte de las necesidades y vicisitudes originadas por la crisis, y han contribuido en cierta medida a mantener las condiciones sociales; no obstante, muchas personas la han perdido a causa de la pobreza y la exclusión social (FOESSA, 2014).

Asimismo, los cambios generados en las políticas económicas y sociales, han provocado un aumento de la demanda de ayudas institucionales al mismo tiempo que han favorecido la aparición de nuevos perfiles de usuarios, muy distintos a los colectivos clásicos (Domínguez, 2017). Se trata de usuarios que nunca antes habían sufrido privación económica, pero que actualmente se han visto afectados por la crisis y han tenido que recurrir a las ayudas sociales para cubrir sus necesidades. Sin embargo, es un colectivo que no se percibe como pobre sino que considera que su situación es circunstancial, pues reconocerse pobre significaría aceptar que su condición fuera duradera (Díaz-Méndez et al., 2019).

Estos nuevos usuarios, de clase media, habían subsistido hasta ahora con los pocos recursos que tenían gracias a su salario mensual que les permitía satisfacer las necesidades básicas. Pero, la pérdida de empleo y precarización laboral derivadas de la crisis, condujo a muchas personas y familias al endeudamiento e imposibilidad de afrontar pagos y préstamos iniciados en época de prosperidad económica, viéndose obligados a acudir a los Servicios Sociales. Estas razones, son las que han convertido a la denominada clase media en el nuevo perfil de demandante de dichos Servicios Sociales (López, Ontiveros, Redondo, \& Herrera, 2015), de la que cabría destacar a jóvenes de mediana edad y trabajadores con empleos precarios, que en muchos casos 
han tenido que recurrir también a la economía sumergida para poder salir adelante. En este escenario, las ayudas informales ofrecidas por la familia, redes vecinales $u$ organizaciones no institucionales, han constituido una herramienta de apoyo social que ha permitido sobrellevar en cierta manera los periodos de inestabilidad (Domínguez, 2017).

Por otro lado, hay personas que prescinden de las instituciones de bienestar social a pesar de vivir situaciones de escasez, puesto que lo consideran bochornoso y estigmatizador. Pues, el suministro de alimentos o provisión de renta por parte del Estado u organizaciones benéficas, genera "vergüenza social". Esta vergüenza actúa como un mecanismo regulador y disciplinario, que ante situaciones de grave recesión económica puede resultar perverso, dado que paraliza la solicitud de prestaciones originando un efecto contrario a los fines de la protección social y el bienestar (Martín et al., 2020).

A este respecto, Domínguez (2017) propone el diseño de intervenciones por parte de los Servicios Sociales que garanticen la inclusión social de los colectivos vulnerables, apostando por su empoderamiento y capacitación para mejorar su situación por sus propios medios y habilidades, y no solo limitar tales intervenciones a la prestación de ayudas económicas.

\subsection{La alimentación en tiempos de crisis}

Tras épocas de recurrente malnutrición en el pasado, en las sociedades industrializadas se ha causado una sensación de abundancia alimentaria generalizada, al declararse que todo el mundo tiene garantizada la accesibilidad a la comida (GraciaArnaiz, 2014). Pues la alimentación pasó de ser un privilegio, a ser reconocida internacionalmente como un derecho contemplado en el artículo 25 de la Declaración Universal de los Derechos Humanos (ONU, 1948); sin embargo, desafortunadamente este derecho no se ha aplicado en los países más empobrecidos del mundo (GraciaArnaiz, 2012). A este respecto, cabe destacar que los cambios sociopolíticos y económicos efectuados a nivel internacional en la última década, también han puesto en cuestionamiento tal derecho en algunos países de Europa como España, y aunque, ciertamente la situación actual del país no se pueda equiparar a las crisis alimentarias vividas anteriormente, la condición de escasez experimentada por personas con bajos recursos, las han obligado a seguir estrategias de subsistencia y limitar la ingesta de 
alimentos (Gracia-Arnaiz, 2014); lo que pone de manifiesto, la estrecha relación entre la jerarquía social y el patrón de consumo alimentario, que evidencia a su vez, la relación entre dicha jerarquía y la desigualdad social en el acceso (Muñoz-Sánchez \& Pérez Flores, 2015).

Asimismo, una dieta saludable y equilibrada requiere la ingesta variada de alimentos (SENC, 2018) cuyo coste podría limitar el acceso a las personas de escasos medios económicos. Pues, en situaciones de carencia, la selección de alimentos no se realiza en base a las preferencias ni siguiendo una lógica nutricional, sino que su adquisición se efectúa en base a los recursos disponibles, anteponiendo el precio a la calidad, y racionalizando el aprovisionamiento para rentabilizar al máximo dichos recursos (Díaz-Méndez et al., 2019). Este hecho, se contrapone con el discurso de abundancia promovido por las sociedades industrializadas, resultando paradójico que en un contexto donde existe un importante excedente alimentario, no se pueda garantizar el derecho a una alimentación suficiente y adecuada (Gracia-Arnaiz, 2014).

Durante la crisis, millones de personas en España se han visto forzadas a solicitar ayudas alimentarias para satisfacer sus necesidades básicas, siendo los bancos de alimentos, comedores sociales e instituciones humanitarias, los que han contribuido a mitigar la privación alimentaria; no obstante, estos organismos se han visto desbordados dado el incremento de demandantes y la tasa de pobreza (FEGA, 2013).

La mala situación económica por la que atraviesan muchas personas, la han llevado a realizar cambios en sus pautas de consumo, optando por elecciones alimentarias más asequibles y deficitarias (Díaz Méndez, García Espejo, \& Otero Estévez, 2018; Díaz-Méndez et al., 2019), no alcanzando las recomendaciones dietéticas, al excluir alimentos básicos - esenciales para un mantenimiento óptimo del estado nutricional - o limitar su ingesta (Prieto, Solares, \& Patterson, 2018).

Por otro lado, resulta alarmante que las personas con bajos ingresos sean las que mayor tendencia presenten a padecer problemas de sobrepeso u obesidad (Prieto et al., 2018; Villares et al., 2018). Parece ser que la reducción del gasto alimentario también se acompaña de hábitos dietéticos no saludables que favorecen el desarrollo de dichas patologías (Antentas \& Vivas, 2014). E igual de llamativo, resulta el hecho de que este fenómeno también se de en el caso de las personas usuarias de ayudas alimentarias, quienes muestran un bajo consumo de alimentos básicos como lácteos, frutas, verduras 
y pescado, además de presentar un perfil calórico inadecuado por el bajo nivel de hidratos de carbono, y altos niveles de proteínas y grasas saturadas. En este sentido, Prieto et al., (2018) consideran la necesidad de crear intervenciones de ayuda alimentaria que provean a los usuarios de una alimentación adecuada, y fomentar la adquisición de hábitos alimentarios saludables mediante programas de educación nutricional.

\section{OBJETIVOS}

Fruto de la revisión bibliográfica anterior, la presente investigación pretende aproximarse a los Servicios Sociales de la Ciudad Autónoma de Melilla, estableciendo los siguientes objetivos:

-Definir el perfil de los usuarios de Servicios Sociales de Melilla.

-Determinar la relación entre las características sociodemográficas y culturales, y el estilo de vida.

-Evaluar el patrón de consumo alimentario y su grado de cumplimiento con respecto a las recomendaciones dietéticas.

\section{METODOLOGÍA}

La presente investigación se ha desarrollado de conformidad con el Reglamento General de Protección de Datos y con la Ley Orgánica 3/2018, de 5 de diciembre, de Protección de Datos Personales y garantía de los derechos digitales, garantizando en todo momento el anonimato de los participantes y confidencialidad de la información obtenida. Dicha investigación presenta un diseño metodológico observacional, descriptivo y de corte transversal.

\subsection{Población y muestra}

La población objeto de estudio está conformada por usuarios de los Centros de Servicios Sociales Comunitarios de Melilla. Para la investigación, solo se ha tenido acceso a dos de los tres centros dado que uno de ellos se hallaba cerrado en el momento de la recopilación de datos.

Para el muestreo se ha empleado el método no probabilístico accidental, y como criterios de inclusión se han considerado los siguientes: ser beneficiario o solicitante de 
alguna prestación social, y la voluntariedad de los usuarios para su participación en la investigación. La muestra total ha sido configurada por 50 participantes, siendo 28 de un centro y 22 del otro, con edades comprendidas entre los 26 y 76 años de los cuales 33 fueron mujeres y 17 hombres.

\subsection{Variables de estudio}

Partiendo de los resultados de la investigación, definiremos el perfil de los usuarios de Servicios Sociales de Melilla a través de las características sociodemográficas y culturales (variables independientes) de los mismos, y determinaremos su relación con los hábitos alimentarios y el grado de cumplimiento de las recomendaciones dietéticas (variables dependientes).

\subsection{Instrumento}

El instrumento utilizado para la recogida de datos ha sido una encuesta ad hoc (ver Anexo I) organizada en cuatro bloques. El primero está constituido por variables sociodemográficas, el segundo por los antecedentes y hábitos de salud, el tercero por hábitos alimentarios y estilo de vida, y el cuarto por el número y motivación de las visitas a los Servicios Sociales. El segundo instrumento empleado en el estudio ha sido la tabla de recomendaciones de la Sociedad Española de Nutrición Comunitaria (SENC, 2004) disponible en el Anexo II, con el fin de evaluar el patrón dietético y determinar el grado de cumplimiento de tales recomendaciones.

\subsection{Técnica de recogida y análisis de datos}

La recopilación de datos tuvo lugar en los meses de julio y agosto de 2020. La encuesta se entregó físicamente a los participantes, quienes dedicaron una media de 15 minutos para su cumplimentación anónima e individual.

El análisis de datos se efectuó mediante el paquete estadístico IBM SPSS Statistics Versión 22.0 para Windows.

\section{RESULTADOS}

\subsection{Perfil de usuario de los Servicios Sociales de Melilla.}

Para responder a este objetivo, se han analizado dos tipo de variables: sociodemográficas y culturales, expuestos en la Tabla 1. 
Tabla 1. Variables sociodemográficas y culturales.

\begin{tabular}{|c|c|}
\hline \multirow{2}{*}{$\begin{array}{l}\text { Variable } \\
\text { Edad }\end{array}$} & Media \pm SD ó n(\%) \\
\hline & $45.08 \pm 10.79$ \\
\hline Entre 18 y 30 & $7(14 \%)$ \\
\hline Entre 31 y 44 & $19(38 \%)$ \\
\hline Entre 45 y 65 & $22(44 \%)$ \\
\hline Mayor de 65 & $2(4 \%)$ \\
\hline \multicolumn{2}{|l|}{ Sexo } \\
\hline Mujeres & $33(66 \%)$ \\
\hline Hombres & $17(34 \%)$ \\
\hline \multicolumn{2}{|l|}{ Estado civil } \\
\hline Soltero/a & $7(14 \%)$ \\
\hline Casado/a & $26(52 \%)$ \\
\hline Pareja de hecho & $1(2 \%)$ \\
\hline Separado/a & $4(8 \%)$ \\
\hline Divorciado/a & $9(18 \%)$ \\
\hline Viudo/a & $3(6 \%)$ \\
\hline Tiene hijos & $48(96 \%)$ \\
\hline Número de Hijos/as & $2.62 \pm 1.29$ \\
\hline \multicolumn{2}{|l|}{ País de nacimiento } \\
\hline España & $17(34 \%)$ \\
\hline Marruecos & $32(64 \%)$ \\
\hline Rumanía & $1(2 \%)$ \\
\hline $\mathbf{N}^{0}$ personas que habitan en el hogar & $3.96 \pm 1.52$ \\
\hline \multicolumn{2}{|l|}{ Nacionalidad } \\
\hline Española & $25(50 \%)$ \\
\hline Marroquí & $24(48 \%)$ \\
\hline Rumana & $1(2 \%)$ \\
\hline \multicolumn{2}{|l|}{ Etnia } \\
\hline Bereber & $35(70 \%)$ \\
\hline Árabe & $5(10 \%)$ \\
\hline Española & $7(14 \%)$ \\
\hline Rumana & $1(2 \%)$ \\
\hline Mestiza & $1(2 \%)$ \\
\hline \multicolumn{2}{|l|}{ Nivel de estudios } \\
\hline Sin Estudios & $27(54 \%)$ \\
\hline Elementales o Graduado escolar & $12(24 \%)$ \\
\hline FP. Bachillerato o similar & $6(12 \%)$ \\
\hline Universitarios o similar & $5(10 \%)$ \\
\hline \multicolumn{2}{|l|}{ Situación Laboral } \\
\hline Desempleado/a & $40(80 \%)$ \\
\hline Jubilado/a ó pensionista & $3(6 \%)$ \\
\hline Ama de casa & $1(2 \%)$ \\
\hline Trabajador/a por cuenta ajena & $5(10 \%)$ \\
\hline Otros (no ha trabajado nunca) & $1(2 \%)$ \\
\hline $\mathrm{N}^{0}$ personas del hogar que trabajan & $0.06 \pm 0.24$ \\
\hline \multicolumn{2}{|l|}{ Propiedad de la vivienda } \\
\hline En propiedad & $7(14 \%)$ \\
\hline En propiedad, pero con hipoteca & $3(6 \%)$ \\
\hline
\end{tabular}




\begin{tabular}{cc} 
Alquilada & $32(64 \%)$ \\
Cedida & $4(8 \%)$ \\
Usufructo & $3(6 \%)$ \\
Otros & $1(2 \%)$ \\
\hline
\end{tabular}

Fuente: elaboración propia.

Los resultados muestran que los participantes tienen una edad media de $45.08 \pm$ 10.79 años, siendo el grupo de edad de 45 a 65 años el de mayor presencia. Además, según el sexo, son las mujeres (66\%) quienes acuden en mayor medida a los Servicios Sociales, y según la etnia, los bereberes son los de mayor representación en dicha institución.

En relación a la unidad familiar, afirman tener hijos el 96\% de los encuestados, de los cuales el 92\% convive con ellos en el hogar, mientras que el resto (8\%) alega no vivir con ellos por varios motivos: bien no tienen la custodia, o sus hijos están emancipados. La media obtenida para esta variable es de $2.62 \pm 1.29$, siendo mayoritariamente 2 y 3 los hijos que tienen los participantes (36\% y $24 \%$ respectivamente). Por otro lado, un 56\% vive con su pareja o cónyuge, aunque según su estado civil, solo el $54 \%$ afirma estar casado o tener pareja de hecho, mientras que el $26 \%$ está separado o divorciado, el $14 \%$ es soltero, y el $6 \%$ es viudo. Así, la media de personas que habitan en el hogar es de $3.96 \pm 1.52$, siendo 7 el número máximo de habitants en el hogar.

Respecto a la carga familiar, cabe destacar el alto porcentaje de familias monoparentales constituido por mujeres (principalmente de edades comprendidas entre los 45 y 65 años), con un valor del 36\% de la muestra total, de la cual el $88.8 \%$ está en situación de desempleo, y el resto, bien no ha trabajado nunca (5.6\%) o es pensionista (5.6\%). Además, el $61 \%$ de estas mujeres no percibe ninguna prestación, y de aquellas en situación de desempleo el 68.7\% es de larga duración (más de 1 año sin trabajar).

En relación a la situación laboral, solo trabaja el 10\% siendo mayor la proporción en hombres (80\%) que en mujeres (20\%). Asimismo, la fuerza de trabajo de los miembros de la unidad familiar es prácticamente nula con una media de $0.06 \pm 0.24$, y solo el $6 \%$ de los participantes confirma que hay algún miembro trabajando. 
Expuesto lo anterior, no resulta extraño que cuando se les pregunta sobre el nivel de renta, se consideren casi en su totalidad como muy pobre o pobre $(84 \%)$ frente a un $16 \%$ que la percibe como suficiente o excelente ( $14 \%$ y $2 \%$ respectivamente).

En relación al nivel educativo, la mayoría (54\%) carece de estudios, y solo un $10 \%$ cuenta con titulación universitaria, lo que explicaría además que la generalidad $(80 \%)$ de ellos solo desempeñe o haya desempeñado profesiones de baja cualificación, según mostraron los resultados. Por otro lado, cabe señalar que los participantes en posesión de estudios universitarios pertenecían a diferentes culturas: española (40\%), bereber (40\%) y árabe (20\%); si bien se aprecia generalmente un menor nivel educativo en la cultura bereber y árabe, aunque sí presentan un mayor dominio de idiomas que las restantes.

Respecto a la vivienda, solo un porcentaje escaso de la muestra la tiene en propiedad (14\%), le ha sido cedida (8\%) o la posee en usufructo $(6 \%)$; mientras que la mayoría $(64 \%)$ vive de alquiler o en alojamiento alternativo $(2 \%)$. Y en relación al equipamiento, no en todos los casos los participantes cuentan con elementos tan básicos como cocina, lavadora o frigorífico; y solo algunos de ellos disponen de ordenador (28\%), acceso a internet (38\%), calefacción (14\%) y aire acondicionado (18\%).

\subsection{Estilo de vida según las características sociodemográficas y culturales.}

Para dar respuesta a este objetivo se han analizado los antecedentes y hábitos de salud (Tabla 2) así como el estilo de vida (Tabla 3) de los participantes. 
Tabla 2. Antecedentes y hábitos en salud.

\begin{tabular}{|c|c|}
\hline Variable & Media \pm SD ó n (\%) \\
\hline Enfermedad crónica & $20(40 \%)$ \\
\hline \multicolumn{2}{|l|}{ Enfermedades crónicas más comunes } \\
\hline Hipertensión & $5(10 \%)$ \\
\hline Diabetes & $3(6 \%)$ \\
\hline Asma & $3(6 \%)$ \\
\hline Artrosis & $3(6 \%)$ \\
\hline Ingreso hospitalario & $31(62 \%)$ \\
\hline \multicolumn{2}{|l|}{ Ingresos hospitalarios más comunes } \\
\hline Intervención quirúrgica & $19(38 \%)$ \\
\hline Accidente & $6(12 \%)$ \\
\hline Automedicación & $10(20 \%)$ \\
\hline Antibióticos sin prescripción & $6(12 \%)$ \\
\hline \multicolumn{2}{|l|}{ Vacuna hijos } \\
\hline Sí & $46(95.8 \%)$ \\
\hline No & $1(2.1 \%)$ \\
\hline $\mathrm{NS} / \mathrm{NC}$ & $1(2.1 \%)$ \\
\hline
\end{tabular}

Fuente: Elaboración propia.

En relación a los antecedentes de salud, los resultados revelan que el $40 \%$ de la muestra presenta enfermedades crónicas siendo la hipertensión la más común de ellas, seguida de diabetes, asma y artrosis en la misma proporción (6\%); y que un $62 \%$ ha requerido ingreso hospitalario, siendo la intervención quirúrgica (38\%) el principal motivo, y los accidentes (12\%) el segundo. Tanto la presencia de enfermedades crónicas como la hospitalización son más frecuentes en las personas de 45 a 65 años.

Según el sexo, las mujeres han sido las que mayor ingreso hospitalario han tenido (63.6\%) en comparación con los hombres (58.8\%), y las que más presentan enfermedades crónicas (48.5\%) frente a éstos (23.5\%). Y según la cultura, es en proporción la española $(57.1 \%)$, la que muestra un mayor número de personas con tales enfermedades, y la bereber la de mayor hospitalización (66.7\%).

Respecto a los hábitos en salud, un $20 \%$ de los participantes confiesa haberse automedicado alguna vez y un $12 \%$ haber tomado antibióticos sin prescripción médica, dándose ambos casos con mayor frecuencia en hombres que en mujeres. Por otro lado, con referencia a la vacunación, el 95,8 \% afirma habérsela administrado a sus hijos siguiendo el calendario vacunal, mientras un $2.1 \%$ asegura que sus hijos no han 
recibido todas las vacunas por indocumentación, y el otro $2,1 \%$ restante alega desconocer si su hijo ha sido vacunado al estar ausente en su vida.

En relación al estilo de vida (Tabla 3), los resultados sobre la percepción de los participantes, indican que la generalidad (70\%) de ellos considera su estilo de vida saludable: un $62 \%$ la califica como saludable y un $8 \%$ como muy saludable; mientras que un $28 \%$ la define como poco saludable y un $2 \%$ como nada saludable. A este respecto, cabe señalar que la percepción generalizada de un estilo de vida saludable se contrapone con los datos sobre frecuencia $(12.92 \pm 13.25)$ de actividad física (Tabla 4) y dedicación a actividades sedentarias (27.56 \pm 7.22$)$.

Así, en la Tabla 4 se observa que existe un alto porcentaje (44\%) de participantes que no realiza ningún tipo de actividad física, a pesar del alto nivel de importancia que los encuestados le otorgan al ejercicio físico. Además, tras analizar conjuntamente la frecuencia mensual y el tiempo dedicado al deporte, se obtuvo como resultado que solo el 48\% cumple con las recomendaciones de la OMS (2010) de realizar al menos 150 minutos de actividad semanal moderada. Igualmente, se observa que según sexo, edad y etnia, son más activos: hombres que mujeres, jóvenes en edades comprendidas entre los 18 y los 30 años, y cultura bereber. Y respecto a las actividades sedentarias (Tabla 3) el 96\% realiza dicho tipo de actividades, y un 38\% le dedica más de 2 horas diarias siendo la frecuencia mayor en hombres, adultos de edades comprendidas entre los 31 y 44 años, y cultura española.

Tabla 3. Estilo de vida.

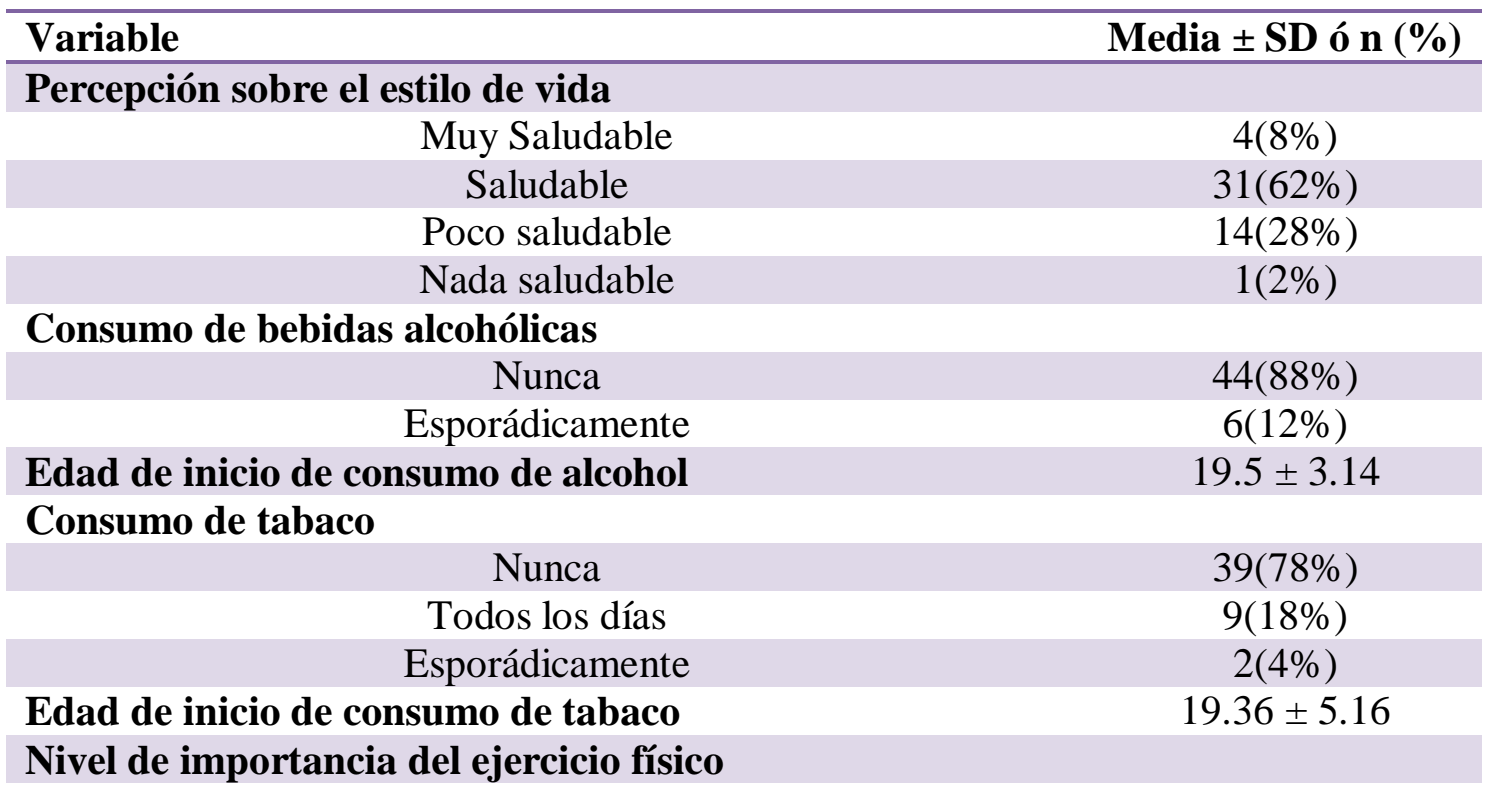




\begin{tabular}{|c|c|}
\hline Nada & $2(4 \%)$ \\
\hline Regular & $20(40 \%)$ \\
\hline Bastante & $28(56 \%)$ \\
\hline \multicolumn{2}{|l|}{ Práctica de ejercicio físico } \\
\hline Ninguno & $22(44 \%)$ \\
\hline 30 minutos & $3(6 \%)$ \\
\hline 45 minutos & $1(2 \%)$ \\
\hline 60 minutos & $11(22 \%)$ \\
\hline$>60$ minutos & $13(26 \%)$ \\
\hline \multicolumn{2}{|l|}{ Dedicaría más tiempo al ejercicio físico } \\
\hline Nada & $4(8 \%)$ \\
\hline Regular & $21(42 \%)$ \\
\hline Bastante & $21(42 \%)$ \\
\hline Indiferente & $4(8 \%)$ \\
\hline Actividades sedentarias & $48(96 \%)$ \\
\hline Horas diarias dedicadas a la actividades sedentarias & $2.2 \pm 1.58$ \\
\hline \multicolumn{2}{|l|}{ Horas de sueño diarias } \\
\hline$<7$ horas & $29(58 \%)$ \\
\hline 7-8 horas & $19(38 \%)$ \\
\hline$>8$ horas & $2(4 \%)$ \\
\hline
\end{tabular}

Fuente: Elaboración propia

Tabla 4. Práctica de actividad física.

\begin{tabular}{|cc}
\hline Variable & Media \pm SD ó n (\%) \\
\hline Frecuencia mensual de actividades deportivas & \\
0 & $22(44 \%)$ \\
4 & $2(4 \%)$ \\
5 & $1(2 \%)$ \\
8 & $1(2 \%)$ \\
12 & $3(6 \%)$ \\
20 & $4(8 \%)$ \\
24 & $1(2 \%)$ \\
25 & $1(2 \%)$ \\
30 & $15(30 \%)$ \\
\hline
\end{tabular}

Fuente: Elaboración propia

En relación a las bebidas alcohólicas (Tabla 3), solo un $12 \%$ lo toma de manera esporádica siendo el consumo idéntico en ambos sexos y la edad media de inicio $19.5 \pm$ 3.14 años. Y en lo que respecta al tabaco, el $22 \%$ de los participantes reconoce ser fumador resultando significativa la diferencia entre sexos y siendo mayor el consumo en hombres $(73 \%)$ que en mujeres (27\%). La edad media de inicio para esta variable es de $19.36 \pm 5.16$ años. Tanto el consumo de bebidas alcohólicas como de tabaco, presentó 
una mayor frecuencia en la cultura española y grupo de edad comprendido entre los 45 y 65 años.

Para finalizar, cabría destacar el elevado porcentaje (58\%) de participantes que afirmó dedicar al sueño menos de 7 horas diarias frente a un $38 \%$ que le dedica de 7 a 8 horas y un $4 \%$ que duerme más de 8 horas. Asimismo, atendiendo a sexo, edad y etnia respectivamente, los datos obtenidos reflejan que los hombres, jóvenes de 18 a 30 años, y de cultura española son los que menos duermen; y que las mujeres, mayores de 65 años, y árabes son los que más duermen.

\subsection{Patrón de consumo alimentario y grado de cumplimiento de las recomendaciones dietéticas.}

Para este objetivo nos centramos principalmente en dos ítems: número de tomas diarias y frecuencia de consumo de alimentos.

Los resultados revelan que del total de la muestra solo realizan 2 tomas el 14\%, 3 tomas el 46\%, 4 tomas el 34\% y 5 tomas el $6 \%$. Y según las distribución de la ingesta diaria realizan el desayuno el $96 \%$, media mañana solo el $8 \%$, almuerzo el $100 \%$, merienda el $62 \%$ y cena el $66 \%$.

Atendiendo al sexo (Tabla 5), cabe mencionar que la totalidad de los hombres realizan dos de las comidas principales: desayuno y almuerzo; mientras que en mujeres el $6,1 \%$ prescinde del primero. Otra diferencia es que ningún hombre ingiere alimentos a media mañana mientras que en mujeres se observa que lo hace el $8 \%$, y que las mujeres realizan con mayor frecuencia la merienda que la cena, contrariamente al caso de los hombres.

Tabla 5. Distribución de la ingesta diaria según el sexo.

\begin{tabular}{cccccc}
\hline & $\begin{array}{c}\text { Desayuno } \\
\mathbf{n}(\%)\end{array}$ & $\begin{array}{c}\text { Media mañana } \\
\mathbf{n}(\%)\end{array}$ & $\begin{array}{c}\text { Almuerzo } \\
\mathbf{n}(\%)\end{array}$ & $\begin{array}{c}\text { Merienda } \\
\mathbf{n}(\%)\end{array}$ & $\begin{array}{c}\text { Cena } \\
\mathbf{n}(\%)\end{array}$ \\
\hline Hombres & 17 & 0 & 17 & 8 & 11 \\
& $(100 \%)$ & $(0 \%)$ & $(100 \%)$ & $(47.1 \%)$ & $(64.7 \%)$ \\
Mujeres & 31 & 4 & 33 & 23 & 22 \\
& $(93.9 \%)$ & $(12.1 \%)$ & $(100 \%)$ & $(69.7 \%)$ & $(66.7 \%)$ \\
Totales & 48 & 4 & 50 & 31 & 33 \\
& $(96 \%)$ & $(8 \%)$ & $(100 \%)$ & $(62 \%)$ & $(66 \%)$ \\
\hline
\end{tabular}

Fuente: elaboración propia 
A continuación, la Tabla 6 recoge la distribución de la ingesta diaria según la etnia, donde se observa que seguidamente a la cultura rumana y mestiza (a la cual pertenece un solo participante en ambos casos), la española es la que realiza con mayor frecuencia las 5 comidas en comparación con la bereber y la árabe. Además, en la bereber se contempla que una de las comidas principales, el desayuno, no está cubierto en todos los casos, y en la cultura árabe se omite la media mañana.

Tabla 6. Distribución de la ingesta diaria según la etnia.

\begin{tabular}{cccccc}
\hline & $\begin{array}{c}\text { Desayuno } \\
\mathbf{n}(\%)\end{array}$ & $\begin{array}{c}\text { Media mañana } \\
\mathbf{n}(\%)\end{array}$ & $\begin{array}{c}\text { Almuerzo } \\
\mathbf{n}(\%)\end{array}$ & $\begin{array}{c}\text { Merienda } \\
\mathbf{n}(\%)\end{array}$ & $\begin{array}{c}\text { Cena } \\
\mathbf{n}(\%)\end{array}$ \\
\hline española & 7 & 2 & 7 & 5 & 6 \\
& $(100 \%)$ & $(28.6 \%)$ & $(100 \%)$ & $(71.4 \%)$ & $(85.7 \%)$ \\
bereber & 34 & 1 & 36 & 21 & 22 \\
& $(94.4 \%)$ & $(2.8 \%)$ & $(100 \%)$ & $(58.3 \%)$ & $(61.1 \%)$ \\
árabe & 5 & 0 & 5 & 3 & 3 \\
& $(100 \%)$ & $(0 \%)$ & $(100 \%)$ & $(60 \%)$ & $(60 \%)$ \\
rumana & 1 & 1 & 1 & 1 & 1 \\
& $(100 \%)$ & $(100 \%)$ & $(100 \%)$ & $(100 \%)$ & $(100 \%)$ \\
mestiza & 1 & 1 & 1 & 1 & 1 \\
& $(100 \%)$ & $(100 \%)$ & $(100 \%)$ & $(100 \%)$ & $(100 \%)$ \\
Totales & 48 & 4 & 50 & 31 & 33 \\
& $(96 \%)$ & $(8 \%)$ & $(100 \%)$ & $(62 \%)$ & $(66 \%)$ \\
\hline
\end{tabular}

Fuente: Elaboración propia.

Atendiendo a la edad (Tabla 7), todos los grupos salvo el comprendido entre los 45 y 65 años, tiene asegurados al 100\% dos comidas principales: desayuno y almuerzo en el caso de adultos de 31 a 44 años, y mayores de 65; y almuerzo y cena en el caso de los jóvenes de 18 a 30 años.

Según las diferentes tomas, los jóvenes de 18 a 30 realizan con menor frecuencia el desayuno con respecto a los demás grupos, y los mayores de 65 años son los únicos que omiten en su totalidad la media mañana, y que además presenta una menor frecuencia de consumo respecto a la merienda y la cena. En sentido opuesto, adultos de 31 a 44 años y mayores de 65 son quienes desayunan con mayor frecuencia (100\%), jóvenes de 18 a 30 años son quienes realizan con mayor asiduidad media mañana y cena, y adultos de 45 a 65 años quienes meriendan con mayor frecuencia. 
Tabla 7. Distribución de la ingesta diaria según la edad.

\begin{tabular}{cccccc}
\hline & $\begin{array}{c}\text { Desayuno } \\
\text { n }(\%)\end{array}$ & $\begin{array}{c}\text { Media mañana } \\
\text { n (\%) }\end{array}$ & $\begin{array}{c}\text { Almuerzo } \\
\text { n }(\%)\end{array}$ & $\begin{array}{c}\text { Merienda } \\
\text { n }(\%)\end{array}$ & $\begin{array}{c}\text { Cena } \\
\text { n }(\%)\end{array}$ \\
\hline De 18 a 30 & 6 & 1 & 7 & 4 & 7 \\
& $(85.7 \%)$ & $(14.3 \%)$ & $(100 \%)$ & $(57.1 \%)$ & $(100 \%)$ \\
De 31 a 44 & 19 & 1 & 19 & 12 & 10 \\
& $(100 \%)$ & $(5.3 \%)$ & $(100 \%)$ & $(63.2 \%)$ & $(52.6 \%)$ \\
\hline De 45 a 65 & 21 & 2 & 22 & 14 & 15 \\
& $(95.5 \%)$ & $(9.1 \%)$ & $(100 \%)$ & $(63.6 \%)$ & $(68.2 \%)$ \\
Mayor de 65 & 2 & 0 & 2 & 1 & 1 \\
& $(100 \%)$ & $(0 \%)$ & $(100 \%)$ & $(50 \%)$ & $(50 \%)$ \\
Totales & 48 & 4 & 50 & 31 & 33 \\
& $(96 \%)$ & $(8 \%)$ & $(100 \%)$ & $(62 \%)$ & $(66 \%)$ \\
\hline
\end{tabular}

Fuente: Elaboración propia.

A continuación (Tabla 8), se expone el grado de cumplimiento de las recomendaciones dietéticas por grupos de alimentos. Según éstos, se aprecia que una alta proporción de la muestra no satisface las recomendaciones de consumo de frutas, verduras y cereales, siendo en el primer caso nulo el porcentaje que realiza una ingesta adecuada, en el segundo caso un $2 \%$, y en el tercero únicamente tiene un consumo adecuado el 14\%. Para legumbres, lácteos y pescado, dicho porcentaje presenta un valor del $34 \%, 40 \%$ y $48 \%$, respectivamente.

En lo relativo al consumo de carnes, la proporción de personas con un consumo inferior y superior es la misma (20\%), mientras que solo un $10 \%$ realiza un consumo adecuado; y para el consumo de huevos, el porcentaje es similar para ambos extremos siendo solo un $30 \%$ el que realiza una ingesta adecuada.

Por otro lado, en referencia a los alimentos de consumo ocasional, realizan una ingesta excesiva de refrescos con gas el $54 \%$, de bollería industrial el $46 \%$, de zumos industriales el $40 \%$, de salsas industriales el $34 \%$, de embutidos el $26 \%$, de chocolates y derivados el $22 \%$, y de snacks y golosinas el $6 \%$.

Asimismo, casi la tercera parte de los participantes muestra un bajo consumo de agua. 
Tabla 8. Evaluación nutricional del consumo de alimentos.

\begin{tabular}{|c|c|}
\hline Variable & Media \pm SD ó n (\%) \\
\hline \multicolumn{2}{|l|}{ Lácteos y derivados } \\
\hline Inferior & $30(60 \%)$ \\
\hline Normal & $19(38 \%)$ \\
\hline Superior & $1(2 \%)$ \\
\hline \multicolumn{2}{|l|}{ Frutas } \\
\hline Inferior & $50(100 \%)$ \\
\hline \multicolumn{2}{|l|}{ Verduras } \\
\hline Inferior & $49(98 \%)$ \\
\hline Normal & $1(2 \%)$ \\
\hline \multicolumn{2}{|l|}{ Cereales } \\
\hline Inferior & $41(82 \%)$ \\
\hline Normal & $7(14 \%)$ \\
\hline Superior & $2(4 \%)$ \\
\hline \multicolumn{2}{|l|}{ Legumbres } \\
\hline Inferior & $33(66 \%)$ \\
\hline Normal & $15(30 \%)$ \\
\hline Superior & $2(4 \%)$ \\
\hline \multicolumn{2}{|l|}{ Carnes } \\
\hline Inferior & $20(40 \%)$ \\
\hline Normal & $10(20 \%)$ \\
\hline Superior & $20(40 \%)$ \\
\hline \multicolumn{2}{|l|}{ Huevos de gallina } \\
\hline Inferior & $18(36 \%)$ \\
\hline Normal & $15(30 \%)$ \\
\hline Superior & $17(34 \%)$ \\
\hline \multicolumn{2}{|l|}{ Pescado } \\
\hline Inferior & $26(52 \%)$ \\
\hline Normal & $12(24 \%)$ \\
\hline Superior & $12(24 \%)$ \\
\hline \multicolumn{2}{|l|}{ Embutidos } \\
\hline No consume & $30(60 \%)$ \\
\hline Consumo moderado & $7(14 \%)$ \\
\hline Consumo excesivo & $13(26 \%)$ \\
\hline \multicolumn{2}{|l|}{ Chocolates y derivados } \\
\hline No consume & $29(58 \%)$ \\
\hline Consumo moderado & $10(20 \%)$ \\
\hline Consumo excesivo & $11(22 \%)$ \\
\hline \multicolumn{2}{|l|}{ Bollería industrial } \\
\hline No consume & $15(30 \%)$ \\
\hline Consumo moderado & $12(24 \%)$ \\
\hline Consumo excesivo & $23(46 \%)$ \\
\hline \multicolumn{2}{|l|}{ Snacks y golosinas } \\
\hline No consume & $40(80 \%)$ \\
\hline Consumo moderado & $7(14 \%)$ \\
\hline Consumo excesivo & $3(6 \%)$ \\
\hline \multicolumn{2}{|l|}{ Refrescos con gas } \\
\hline No consume & $19(38 \%)$ \\
\hline
\end{tabular}




\begin{tabular}{|c|c|}
\hline Consumo moderado & $4(8 \%)$ \\
\hline Consumo excesivo & $27(54 \%)$ \\
\hline \multicolumn{2}{|l|}{ Zumo de fruta industrial } \\
\hline No consume & $26(52 \%)$ \\
\hline Consumo moderado & $4(8 \%)$ \\
\hline Consumo excesivo & $20(40 \%)$ \\
\hline \multicolumn{2}{|l|}{ Agua } \\
\hline Inferior & $16(32 \%)$ \\
\hline Normal & $25(50 \%)$ \\
\hline Superior & $9(18 \%)$ \\
\hline \multicolumn{2}{|l|}{ Alimentos precocinados } \\
\hline No consume & $45(90 \%)$ \\
\hline Consumo moderado & $5(10 \%)$ \\
\hline \multicolumn{2}{|l|}{ Salsas industriales } \\
\hline No consume & $26(52 \%)$ \\
\hline Consumo moderado & $7(14 \%)$ \\
\hline Consumo excesivo & $17(34 \%)$ \\
\hline
\end{tabular}

Fuente: Elaboración propia.

Estos datos fueron además analizados según sexo, edad y cultura, de modo que para las comparaciones, nos centramos en el consumo deficiente de los diferentes grupos de alimentos y atendiendo a la ingesta excesiva de aquellos de consumo ocasional.

Siguiendo este criterio y atendiendo al sexo, en hombres se observa una mayor carencia alimentaria e ingesta excesiva de alimentos de consumo ocasional (embutidos, bollería, dulces, refrescos, etc.).

Según la edad, los mayores de 65 años son quienes más deficiencias alimentarias presentan, y los jóvenes de 18 a 30 años quienes realizan una ingesta más excesiva de alimentos de consumo ocasional.

Y según la etnia, es en la árabe donde se dan mayores carencias alimentarias, y la española la que presenta una ingesta más excesiva de alimentos de consumo ocasional.

Por último, en lo relativo a técnicas culinarias, de manera global se emplea con mayor frecuencia (semanal) la fritura $(2.42 \pm 1.66)$, y en menor medida el cocido $(2.2 \pm$ 1.24) y el asado $(2 \pm 1.52)$. 
Resulta especialmente llamativo que a pesar de que la mayoría (80\%) de los encuestados afirma conocer los riesgos de una mala alimentación, se hayan obtenido unos resultados tan negativos en cuanto a hábitos alimentarios se refiere.

\section{DISCUSIÓN}

En lo relativo al perfil del beneficiario de ayudas sociales, según la Memoria del Sistema de Información de Usuarios/as de Servicios Sociales (SIUSS, 2012) existe un predominio de mujeres (59.26\%) en los centros de Servicios Sociales, que concuerda con los resultados obtenidos en la actual investigación (66\%).

Domínguez (2017) también coincide en que son las mujeres quienes acuden mayormente a tales centros y añade que éstas son de edades comprendidas entre los 26 y 45 años; siendo este último dato distinto al hallado en la muestra (45-65 años).

Además, varios estudios (Álvarez-Dardet, García, García, Lara, \& Hidalgo, 2010; Menéndez Álvarez-Dardet, Arenas Rojas, Pérez Padilla, \& Lorence Lara, 2012) confirman los datos descritos sobre la presencia en los Servicios Sociales de madres constituyentes de familias monoparentales (36\%) que representan más de un tercio del total de mujeres, siendo más alto los porcentajes de los mencionados estudios $(49.8 \%$ y $41.8 \%$, respectivamente).

Domínguez (2017) justifica esta feminización del perfil de usuario argumentando que son las mujeres quienes suelen proteger y velar por los intereses de la familia, enfrentando los problemas y aportando soluciones.

En lo relativo al estado civil, la mayoría de los usuarios están casados o forman pareja de hecho representando el $54 \%$, separados o divorciados el $26 \%$, viudos el $6 \%$ y solteros el 14\%, resultados muy similares a los revelados por el III Informe sobre los Servicios Sociales en España (CGTS, 2017) donde los beneficiarios casados o con pareja de hecho representaban el 54.8\%, separados o divorciados el $20.4 \%$, viudos el $13.9 \%$ y solteros el $10.8 \%$.

Respecto a la situación laboral, solo el 10\% de los usuarios afirmó estar trabajando, un dato muy desalentador considerando que casi la totalidad de ellos (92\%) tiene familia a cargo y la fuerza de trabajo en el hogar es prácticamente nula $(0.06 \pm$ 
0.24), sin mencionar los pagos hipotecarios y de alquiler que han de enfrentar la mayoría (70\%). En este sentido, cabría señalar además, que el empleo no solo funciona como un factor económico sino que también desempeña una "función integrativa" al generar status (Martínez-Martín et al., 2018), por ello es inconcebible que exista una verdadera inserción social de las personas si está ausente la inserción laboral.

En cierta medida, la alta tasa de desempleo referida anteriormente, podría explicarse por la escasa formación de los participantes. Pues, según la OCDE (2018) las personas sin estudios o de bajo nivel educativo, tienen menos posibilidades de conseguir empleo que aquellas con estudios superiores. Aunque, tampoco estos últimos tienen garantizado el empleo como evidencia el actual estudio con una presencia del $10 \%$ de universitarios desempleados, solicitantes de ayudas sociales.

En referencia a la percepción subjetiva del estilo de vida, un $70 \%$ de los participantes lo considera saludable, no obstante, tal percepción se contradice con los datos obtenidos sobre actividad física y patrón de conducta alimentaria, pues solo un bajo porcentaje (28\%) de la muestra cumple con las recomendaciones sobre actividad física establecidos por la OMS (2010) y en ningún grupo de alimentos básicos está garantizada la ingesta óptima de acuerdo a las pautas marcadas por la SENC (2004).

Asimismo, según la Encuesta Nacional de Salud de 2017 (MSCBS, 2018), en España el 74\% de los ciudadanía valora positivamente su salud, sin embargo, a pesar de que la salud percibida es considerablemente favorable, sigue incrementándose la prevalencia de enfermedades crónicas, siendo la más común la hipertensión arterial $(19,8 \%)$ como fue el caso de nuestro estudio (10\%), colesterol elevado (17,9\%), obesidad $(17,4 \%)$ y diabetes $(7,8 \%)$, esta última con un porcentaje similar al de la presente investigación (6\%).

Sedentarismo, dieta inadecuada, tabaquismo y consumo excesivo del alcohol, constituyen factores de riesgo metabólico que favorecen el desarrollo de las enfermedades previamente enumeradas. Ese tipo de patologías conocidas como Enfermedades No Transmisibles (ENT), conforman según la OMS (2018) la principal causa de muerte en el mundo, siendo responsable del $71 \%$ de los fallecimientos. 
Varios estudios (Godos et al., 2017; Salas-Salvadó et al., 2016; Kargin, Tomaino, \& Serra-Majem, 2019), han demostrado la eficacia de la Dieta Mediterránea en la disminución de la prevalencia y desarrollo de tales enfermedades.

Del mismo modo, la SENC (2018) apuesta por la dieta mediterránea como modelo de dieta saludable, en cuyo patrón alimentario basa sus recomendaciones y de la cual afirma que "proporciona contundentes beneficios para la salud, científicamente probados". Entre dichos beneficios podrían enumerarse la disminución de la morbimortalidad de las enfermedades cardiovasculares por su papel en la prevención del sobrepeso y la obesidad, la prevención del síndrome metabólico, y el efecto protector frente al desarrollo de cáncer. Estos efectos tan positivos sobre la salud, se deben a los elementos bioactivos presentes en la dieta mediterránea como fibra y antioxidantes (flavonoides, polifenoles, fitoesteroles), probióticos, y ácidos grasos esenciales omega-3 y omega-6, y cuyas fuentes principales son frutas, verduras, cereales, legumbres, frutos secos, aceite de oliva y pescado (Urquiaga, Echeverría, Dussaillant, \& Rigotti, 2017). A este respecto, los resultados obtenidos muestran un ínfimo consumo de frutas y verduras con respecto a las recomendaciones dietéticas, y baja cobertura de necesidades alimentarias relativa a cereales (18\%), legumbres (34\%), y pescado (48\%). El estudio ANIBES "ingesta, perfil y fuentes de energía en la población española" (Ruiz et al., 2015), también mostró un bajo consumo de dichos grupos de alimentos, algo realmente preocupante dado el déficit que podría generarse de micronutrientes y fibra, de la que son fuentes principales los alimentos anteriores.

Por otro lado, cabe señalar que es importante considerar la práctica de ejercicio físico en un estilo de vida saludable, pues alimentación y actividad física conforman un binomio inseparable necesario para alcanzar un estado óptimo de salud (SENC, 2015).

Según el estudio ANIBES sobre patrones de actividad física de la población española (Mielgo-Ayuso et al., 2016), edad y sexo son los principales condicionantes de dichos patrones. Según demostró el estudio, los grupos de menor edad practican mayor actividad física que los de edad avanzada, y hombres son más activos que mujeres, lo que avala el resultado obtenido en la presente investigación.

Por último y en relación al estilo de vida y hábitos alimentarios de las distintas etnias, cabe subrayar que según los resultados la cultura bereber es más activa, y la 
española más sedentaria; y que a pesar de la existencia generalizada de un patrón dietético inadecuado, se aprecian ciertas diferencias de manera que la cultura árabe es la que mayor carencias alimentarias presenta y la española la que realiza una ingesta más excesiva de alimentos de consumo ocasional.

Entre las limitaciones de esta investigación, podemos mencionar que la muestra no representa estadísticamente las diferentes culturas. Esto puede deberse principalmente a la gran cantidad de usuarios pertenecientes a una misma comunidad (la bereber) en relación a las demás. Por otra parte, no existen investigaciones previas sobre la realidad planteada en el estudio que nos permita realizar comparaciones.

\section{CONCLUSIONES}

Según los objetivos planteados, podemos deducir las siguientes conclusiones:

El perfil de los usuarios de Servicios Sociales de Melilla está condicionado por diversas variables sociodemográficas: sexo, edad, estado civil, nivel educativo, etnia y situación laboral; observándose un predominio de mujeres casadas de edades comprendidas entre los 45 y 65 años, de cultura bereber, escaso nivel educativo y en situación de desempleo.

En relación al estilo de vida, existe un alto porcentaje de personas con una percepción subjetiva positiva que se contradice con sus hábitos. Si bien, según el sexo son más activos los hombres; según la edad, los jóvenes de 18 a 30 años; y según la cultura, los bereberes.

Respecto a la conducta alimentaria, la población estudiada muestra un patrón de alimentación poco saludable con importantes carencias en varios grupos de alimentos básicos, y bajo grado de cumplimiento de las recomendaciones dietéticas. Esta situación es similar en todos los grupos culturales aunque se aprecia un mayor déficit alimentario en personas de cultura árabe y una ingesta más abusiva de alimentos de consumo ocasional entre personas de cultura española. Según la edad son los mayores de 65 años quienes más deficiencias presentan y jóvenes de 18 a 30 años los que presentan una mayor ingesta de alimentos de consumo ocasional. Según el sexo, los hombres son 
quienes presentan una mayor carencia alimentaria y mayor ingesta de alimentos de consumo ocasional. 


\section{REFERENCIAS BIBLIOGRÁFICAS}

Afonso, A., \& Sastre, S. (2017). La exclusión social en España: factores, colectivos en riesgo y el papel de los bancos de alimentos. En Cátedra Banco de Alimentos de la UPM. Recuperado de https://www.bancodealimentos.es/wpcontent/uploads/2017/10/Exclusion-social.pdf

Alonso, L. E., Rodríguez, C. J. F., \& Rojo, R. I. (2016). Entre la austeridad y el malestar: discursos sobre consumo y crisis económica en España. REIS:Revista Española de Investigaciones Sociológicas, 155, 21-36. https://doi.org/10.5477/cis/reis.155.21

Álvarez-Dardet, S. M., García, M. V. H., García, L. J., Lara, B. L., \& Hidalgo, J. S. (2010). Perfil psicosocial de familias en situación de riesgo. Un estudio de necesidades con usuarias de los Servicios Sociales Comunitarios por razones de preservación familiar. Anales de Psicologia, 26(2), 378-389.

Antentas, J. M., \& Vivas, E. (2014). Impacto de la crisis en el derecho a una alimentación sana y saludable. Informe SESPAS 2014. Gaceta Sanitaria, 28(S1), 58-61. https://doi.org/10.1016/j.gaceta.2014.04.006

Asociación Estatal de Directores y Gerentes en Servicios Sociales. (2018). Evolución de las puntuaciones del índice DEC a nivel general y para cada uno de sus apartados desde 2012 a 2018. . Recuperado de https://www.directoressociales.com/images/INDICEDEC/DEC2018real/REVIS TA web.pdf

Asociación Estatal de Directores y Gerentes en Servicios Sociales. (2018). Índice DEC 2018: índice de desarrollo de los servicios sociales. Recuperado de https://www.directoressociales.com/images/INDICEDEC/DEC2018real/REVIS TA web.pdf

Begega, S. G., \& Balbona, D. L. (2015). Crisis económica y deterioro de los pactos sociales en el sur de Europa: los casos de España y Portugal. Revista Internacional de Sociología, 73(2). https://doi.org/10.3989/ris.2014.03.17 
Carpio, C. C. (2015). La vulnerabilidad laboral de los extranjeros en España. Migraciones Internacionales, 8(2), 41-72. https://doi.org/10.17428/rmi.v8i2.600

CGTS. (2017). III Informe sobre los servicios sociales en España. Recuperado de https://www.cgtrabajosocial.es/files/5de783c0056f8/ISSE_III_WEB.pdf

Chen, T., Hallaert, J.-J., Pitt, A., Qu, H., Queyranne, M., Rhee, A., ... Yackovlev, I. (2018). Inequality and poverty across generations in the European Union. IMF Staff Discussion Notes, 51. Recuperado de https://www.imf.org/en/Publications/Staff-Discussion-

Notes/Issues/2018/01/23/Inequality-and-Poverty-across-Generations-in-theEuropean-Union-45137

Colectivo IOÉ. (2015). Crisis y desigualdades sociales en España. Una lectura crítica desde el Barómetro social de España. Servicios Sociales y Política Social, (108), 46-95.

Díaz-Méndez, C., Estévez, S. O., \& Espejo, I. G. (2019). Contextos de privación alimentaria y crisis en España. En (Re)pensando los retos alimentarios desde las ciencias sociales. Contexto de precarización, respuestas y actuaciones (pp. 41-55). Barcelona, España: UOC.

Díaz Méndez, C., García Espejo, I., \& Otero Estévez, S. (2018). Discursos sobre la escasez: estrategias de gestión de la privación alimentaria en tiempos de crisis. EMPIRIA: Revista de Metodología de Ciencias Sociales, (40), 85-105. https://doi.org/10.5944/empiria.40.2018.22012

Domínguez, D. H. (2017). El cambio de perfil de las personas usuarias de servicios sociales en momentos convulsos. Revista de Trabajo y Acción Social, (60), 79-91.

ECV. (2018a). Tasa de riesgo de pobreza por comunidades y ciudades autónomas en España. Recuperado de https://www.ine.es/jaxiT3/Datos.htm?t=9963\#!tabsgrafico 
ECV. (2018b). Tasa de riesgo de pobreza y/o exclusión social por grupos de edad en

España. Recuperado de

https://www.ine.es/ss/Satellite?L=es_ES\&c=INESeccion_C\&cid=12599416379 44\&p=\%5C\&pagename=ProductosYServicios\%2FPYSLayout\&param1=PYSD etalle\&param $3=1259924822888$

Eraso, A. B., Icart, I. B., Matu, R. O., \& Pastor, I. (2011). Pobreza en España: jóvenes y mujeres en los espacios sociales de la vulnerabilidad. Quaderns de Ciències Socials, (20), 5-28.

Estrategia-Europa2020. (2010). Europa 2020: una estrategia para un crecimiento inteligente, sostenible e integrador. Recuperado de https://eurlex.europa.eu/legal-content/ES/TXT/?uri=celex:52010DC2020

EU-SILC. (2018a). Tasa de riesgo de pobreza y/o exclusión social por nivel de $\begin{array}{llll}\text { educación en } & \text { España. }\end{array}$ https://www.ine.es/ss/Satellite?L=es_ES\&c=INESeccion_C\&cid=12599416379 $44 \& \mathrm{p}=\% 5 \mathrm{C} \&$ pagename $=$ ProductosYServicios $\% 2 \mathrm{FPYSLayout} \&$ param1=PYSD etalle\&param $3=1259924822888$

EU-SILC. (2018b). Tasa de riesgo de pobreza y/o exclusión social por situación laboral. Recuperado de https://www.ine.es/ss/Satellite?L=es_ES\&c=INESeccion_C\&cid=12599416379 44\&p=\%5C\&pagename=ProductosYServicios\%2FPYSLayout \&param1=PYSD etalle\&param $3=1259924822888$

EUROSTAT. (2018). Tasa de jóvenes entre 16 y 29 años en riesgo de pobreza o exclusión social en la UE. Recuperado de https://ec.europa.eu/eurostat/statisticsexplained/index.php/Young_people__social_inclusion\#Young_people_at_risk_of_poverty_or_social_exclusion

EUROSTAT. (2019). Tasa y umbral de riesgo de pobreza, 2017. Recuperado de https://ec.europa.eu/eurostat/statisticsexplained/index.php?title=Income_poverty_statistics/es\&oldid=456699\#Tasa_y _umbral_de_riesgo_de_pobreza 
EUROSTAT. (2020a). Tasa de desempleo en España de 2000 a 2019 . Recuperado de https://es.statista.com/estadisticas/500987/prevision-tasa-de-paro-en-espana/

EUROSTAT. (2020b). Tasa de desempleo en los estados miembros de la UE en enero de 2020. Recuperado de https://www.statista.com/statistics/268830/unemployment-rate-in-eu-countries/

FEGA. (2013). Informe del plan 2013 de ayuda alimentaria a las personas más necesitadas de la unión europea. Recuperado de ttps://www.fega.es/es/PwfGcp/es/_includes/_tcmLinkFilterdotjspyiquesttcmUri yequal45089

Fernández-Villaverde, J., \& Ohanian, L. (2010). The spanish crisis from a global perspective. Documentos de Trabajo ( FEDEA ), (3), 1-60.

FOESSA. (2014). VII Informe sobre exclusión y desarrollo social en España. Recuperado de https://www.foessa2014.es/informe/uploaded/descargas/VII_INFORME.pdf

FOESSA. (2016). Análisis y perspectivas 2016: Expulsión social y recuperación económica. Recuperado de https://caritas-web.s3.amazonaws.com/mainfiles/uploads/2018/03/FOESSA-Análisis-y-Perspectivas-2016-Expulsión-socialy-recuperación-económica.pdf

García-Carro, B., \& Sánchez-Sellero, M. C. (2019). Medición de la pobreza subjetiva en España y su localización espacial. REIS:Revista Española de Investigaciones Sociológicas, 165, 83-100. https://doi.org/10.5477/cis/reis.165.83

García, T. F., \& Cabello, S. A. (2015). Crisis y Estado de bienestar: las políticas sociales en la encrucijada. Revista Tendencias \& Retos, 20(1), 119-132.

Gilsanz, F. J. L. (2014). Pobreza y exclusión social en España: consecuencias estructurales de nuestro modelo de crecimiento. Ehquidad:Revista Internacional de Políticas de Bienestar y Trabajo Social, (1), 91-114. https://doi.org/10.15257/ehquidad.2014.0004 
Godos, J., Zappalà, G., Bernardini, S., Giambini, I., Bes-Rastrollo, M., \& MartinezGonzalez, M. (2017). Adherence to the Mediterranean diet is inversely associated with metabolic syndrome occurrence: a meta-analysis of observational studies. International Journal of Food Sciences and Nutrition, 68(2), 138-148. https://doi.org/10.1080/09637486.2016.1221900

Gómez, J. A. (2012). La quiebra del incompleto sistema de Servicios Sociales en España. Cuadernos de Trabajo Social, 25(1), 63-74. https://doi.org/10.5209/rev_CUTS.2012.v25.n1.38434

Gracia-Arnaiz, M. (2012). Faim dans le monde. En Dictionnaire des cultures alimentaires (pp. 541-555). París, Francia: Presses Universitaries de France.

Gracia-Arnaiz, M. (2014). Comer en tiempos de "crisis": nuevos contextos alimentarios y de salud en España. Salud Pública de México, 56(6), 648-653. https://doi.org/10.21149/spm.v56i6.7392

Hufe, P., Kanbur, R., \& Peichl, A. (2018). Measuring unfair inequality: Reconciling equality of opportunity and freedom from poverty. CEPR Discussion Papers, (12989), 50.

INE. (s.f.). La pobreza y su medición: presentación de diversos métodos de obtención de medidas de pobreza. Recuperado de https://www.ine.es/daco/daco42/sociales/pobreza.pdf

Kargin, D., Tomaino, L., \& Serra-Majem, L. (2019). Experimental outcomes of the mediterranean diet: Lessons learned from the predimed randomized controlled trial. Nutrients, Vol. 11. https://doi.org/10.3390/nu11122991

Lima, M. da P. C., \& Artiles, A. M. (2011). Crisis and trade union challenges in Portugal and Spain: Between general strikes and social pacts. Transfer: European Review of Labour and Research, 17(3), 387-402. https://doi.org/10.1177/1024258911410806 
López, T., Ontiveros, M. L., Redondo, M. D., \& Herrera, P. El perfil cambiante de los $\begin{array}{llll}\text { Servicios } & \text { Sociales. } & \text { Recuperado }\end{array}$ https://reporteroserviciosociales.wordpress.com/2015/05/31/el-perfil-cambiantede-los-servicios-sociales/

Marí-klose, P. (2019). El rejuvenecimiento de la pobreza : perspectivas y nuevos imperativos de la política pública. Cuadernos de Investigación En Juventud, (6), 1-4. https://doi.org/10.22400/cij.6.e027

Martín, M. P. M., Pericacho, C. D. C., \& Gómez, D. C. (2020). Ciudadanía del bienestar durante la crisis en España: el caso de los hogares vulnerables. REIS:Revista Española de Investigaciones Sociológicas, 169, 85-102. https://doi.org/10.5477/cis/reis. 169.85

Martínez-Martín, R., García-Moreno, J. M., \& Lozano-Martín, A. M. (2018). Trabajadores pobres en España. El contexto de la crisis económica como marco para comprender la desigualdad. Papeles de Población, 24(98), 185-218. https://doi.org/10.22185/24487147.2018.98.40

Menéndez Álvarez-Dardet, S., Arenas Rojas, Á. V., Pérez Padilla, J., \& Lorence Lara, B. (2012). Madres usuarias de servicios de prevención familiar: perfil sociodemográfico y evolución. Cuadernos de Trabajo Social, 25(1), 193-203. https://doi.org/10.5209/rev_cuts.2012.v25.n1.38444

Mielgo-Ayuso, J., Aparicio-Ugarriza, R., Castillo, A., Ruiz, E., Ávila, J. M., ArancetaBatrina, J., ... González-Gross, M. (2016). Physical activity patterns of the spanish population are mostly determined by sex and age: Findings in the ANIBES study. PLoS ONE, 11(2), 1-22. https://doi.org/10.1371/journal.pone.0149969

Mir, J. M. V. (2009). La crisis económica actual. Sus orígenes y características. Medidas para salir de la crisis. Revista de Obras Públicas: Órgano Profesional de Los Ingenieros de Caminos, Canales y Puertos, (3496), 19-44.

Morán, M. L., \& Benedicto, J. (2016). Los jóvenes españoles entre la indignación y la desafección política: una interpretación desde las identidades ciudadanas. Última Década, (44), 11-38. 
MSCBS. (2018). Encuesta Nacional de Salud. España 2017. Recuperado de https://www.mscbs.gob.es/estadEstudios/estadisticas/encuestaNacional/encuestaNa c2017/ENSE2017_notatecnica.pdf\%0Ahttps://www.msssi.gob.es/estadEstudios/est adisticas/encuestaNacional/encuestaNac2017/ENSE2017_notatecnica.pdf

MSCBS. (2019). Guía de ayudas sociales y servicios para las familias.

Muñoz-Sánchez, V. M., \& Pérez Flores, A. M. (2015). La alimentación en España en tiempos de crisis: nuevos modelos de valores y consumo. Revista de Humanidades, (25), 169-192. https://doi.org/10.5944/rdh.25.2015.14372

OCDE. (2018). Estudios económicos de la OCDE. Recuperado de https://www.oecd.org/economy/surveys/Spain-2018-OECD-economic-surveyvision-general.pdf

OMS. (2010). Recomendaciones mundiales sobre la actividad física para la salud. Recuperado de https://www.who.int/dietphysicalactivity/factsheet_recommendations/es/

OMS. (2018). Enfermedades no transmisibles. Recuperado de https://www.who.int/es/news-room/fact-sheets/detail/noncommunicable-diseases

ONU. (1948). Declaración Universal de Derechos Humanos. Recuperado de https://www.ohchr.org/EN/UDHR/Documents/UDHR_Translations/spn.pdf

Peláez, A. L., \& Sánchez-Cabezudo, S. S. (2015). Are Social Services equally accessible to all citizens in Spain? Youth and the Spanish Welfare State. Arbor Ciencia, Pensamiento y Cultura, 191(771), a205. https://doi.org/10.3989/arbor.2015.771n1007

Porta, D. Della, Andretta, M., Fernandes, T., O’Connor, F., Romanos, E., \& Vogiatzoglou, M. (2017). Late neoliberalism and its discontents in the economic crisis: comparing social movements in the European periphery. London, UK: Palgrave macmillan.

Prieto, A. B., Solares, S. G., \& Patterson, M. D. los Á. M. (2018). Valoración del estado nutricional de usuarios de ayuda alimentaria. Cuadernos de Trabajo Social, 31(2), 543-558. https://doi.org/10.5209/cuts.53234 
Ruiz, E., Ávila, J. M., Valero, T., Del Pozo, S., Rodriguez, P., Aranceta-Bartrina, J., ... Gonzá, M. (2015). Energy intake, profile, and dietary sources in the spanish population: Findings of the ANIBES study. 4739-4762. https://doi.org/10.3390/nu7064739

Salas-Salvadó, J., Guasch-Ferré, M., Lee, C. H., Estruch, R., Clish, C. B., \& Ros, E. (2016). Protective effects of the Mediterranean Diet on type 2 diabetes and metabolic syndrome. Journal of Nutrition, 146(4), 920S-927S. https://doi.org/10.3945/jn.115.218487

Salom, D. T. (2019). Lucha contra la exclusión social y la pobreza. la necesaria ratificación de la carta social europea revisada y su protocolo sobre reclamaciones colectivas en España. Lex Social: Revista de Derechos Sociales, 9(1), 379-393.

San Juan, B. H. (2019). Una crisis desigual. Información Comercial Española, ICE:Revista de Economía, $\quad$ (906), 89-107. https://doi.org/10.32796/ice.2019.906.6768

SENC. (2004). Guía de la alimentación saludable. Recuperado de https://www.google.es/url?sa=t\&rct=j\&q=\&esrc=s\&source=web\&cd=\&ved=2ahU KEwjDtobn8c_rAhVq5OAKHWa1AggQFjAAegQIBRAB\&url=https\%3A\%2F\% 2Fwww.nutricioncomunitaria.org\%2Fes\%2Fnoticiadocumento\%2F19\&usg=AOvVaw29yNIsWhsCL2wITGRuzOK\&cshid=1599235869629978

SENC. (2015). Pirámide de la alimentación saludable. Recuperado de http://www.nutricioncomunitaria.org/es/noticia/piramide-de-la-alimentacionsaludable-senc-2015

SENC. (2018). Guía de la alimentación saludable para atención primaria y colectivos ciudadanos. Recuperado de http://www.nutricioncomunitaria.org/es/noticia/guiaalimentacion-saludable-ap

SIIS Centro de Documentación y Estudios. (2016). Servicios sociales en España: heterogéneos, pero más bien precarios. Gizarteratuz: Boletín Documental Sobre Asuntos Sociales, (53), 11-13. 
SIUSS. (2012). Memoria del sistema de información de usuarios/as de Servicios $\begin{array}{lll}\text { Sociales } & \text { (S.I.U.S.S.). Recuperado de }\end{array}$ https://www.mscbs.gob.es/ssi/familiasInfancia/ServiciosSociales/Siuss/docs/Memo ria_SIUSS_2012.pdf

Staszczak, D. E. (2019). Recessions and a changing theoretical basis of the recoveries: a view from the state-corporation hegemonic stability theory. Brazilian Journal of Political Economy, 39(4), 675-688. https://doi.org/10.1590/0101-31572019-3013

Stiglitz, J. E. (2012). El precio de la desigualdad: El $1 \%$ de población tiene lo que el 99 \% necesita. Madrid: Taurus.

Urquiaga, I., Echeverría, G., Dussaillant, C., \& Rigotti, A. (2017). Origen, componentes y posibles mecanismos de acción de la dieta mediterránea. Revista Médica de Chile, 145(1), 85-95. https://doi.org/10.4067/s0034-98872017000100012

Villares, J. M. M., De Pipaón, M. S., Sanz, Á. C., Martín, J. J. D., Ferreiro, S. R., López, A. M., ... Folgoso, C. C. (2018). Study on the nutritional status and feeding habits in school-children in Madrid city (Spain) during the economic crisis [ Impacto de la crisis económica en el estado nutricional y en los hábitos alimentarios de escolares de Madrid (España) ]. Nutricion Hospitalaria, 35(5), 1054-1058. https://doi.org/10.20960/nh.1824 
ANEXOS 


\section{ANEXO I: Encuesta}

En cumplimiento con el Reglamento General de Protección de Datos y con la Ley Orgánica 3/2018, de 5 de diciembre, de Protección de Datos Personales y garantía de los derechos digitales se hace expresa mención de que la información proporcionada en este cuestionario será en todo momento de carácter confidencial y con fines de investigación científica.

\section{Datos sociodemográficos (I):}

Edad:

Sexo:

Estado civil:

$\mathrm{N}^{\mathrm{o}}$ hijos:

Lugar de nacimiento hijos: Localidad de residencia (actualmente):

País de nacimiento:

$\mathrm{N}^{\circ}$ personas que habitan en hogar familiar (a su cargo) :

Nacionalidad: Etnia:

Religión que practica:

Idiomas que habla:

Estado civil:

\begin{tabular}{|l|l|}
\hline Soltero/a & \\
\hline Casado/a & \\
\hline Pareja de hecho & \\
\hline Separado/a & \\
\hline Divorciado/a & \\
\hline Viudo/a & \\
\hline NS/NC & \\
\hline
\end{tabular}

\section{Datos sociodemográficos (II):}

Edad marido: Nacionalidad marido: Lugar de nacimiento marido:

Edad mujer: Nacionalidad mujer: Lugar de nacimiento mujer:

Indique el nivel de estudios de la pareja (por favor marque con una $\mathbf{X}$ donde proceda):

\section{Nivel de estudios del marido:}

Elementales o Graduado escolar FP. Bachillerato o similar Universitarios o similar

Nivel de estudios de la mujer:

Elementales o Graduado escolar FP. Bachillerato o similar Universitarios o similar

Profesión del marido: Profesión de la mujer: 
¿Cuántas personas viven con usted?

¿Qué parentesco tienen? Especificar:

\begin{tabular}{|l|l|}
\hline Parentesco (esposo/a; hijos; suegros, etc...) & \\
\hline & \\
\hline & \\
\hline & \\
\hline & \\
\hline & \\
\hline & \\
\hline
\end{tabular}

Situación laboral

\begin{tabular}{|l|l|}
\hline Desempleado $(*)$ & \\
\hline Jubilado o pensionista & \\
\hline Ama de casa & \\
\hline Trabajador por cuenta ajena & \\
\hline Autónomo & \\
\hline Otros (no ha trabajado nunca) & \\
\hline NS/NC & \\
\hline
\end{tabular}

(*) En caso de ser desempleado: ¿Desde cuándo no trabaja? (3, 6, 9 meses: 1, 2 años, etc)

(**) De las personas que viven con usted, ¿Cuántas trabajan?

¿De quién es la propiedad de la vivienda en la que vive?

\begin{tabular}{|l|l|}
\hline En propiedad & \\
\hline En propiedad, pero con hipoteca & \\
\hline Alquilada & \\
\hline Cedida & \\
\hline Usufructo & \\
\hline Otros & \\
\hline NS/NC & \\
\hline
\end{tabular}

Su casa dispone de:

\begin{tabular}{|l|l|l|l|}
\hline Ducha & Teléfono móvil & \\
\hline Bañera & & Teléfono fijo & \\
\hline Cocina & & Ordenador Personal & \\
\hline Frigorífico & & Acceso a Internet & \\
\hline Microondas & & Calefacción & \\
\hline Lavadora & & Aire acondicionado & \\
\hline Televisor & & Brasero o estufa & \\
\hline Radio & Consola videojuegos & \\
\hline
\end{tabular}

\section{Antecedentes y hábitos en salud:}


¿Posee alguna enfermedad crónica? $\square$ Sí $\square$ No Si ha contestado “Sí”, especifique cuál:

¿Ha sido hospitalizado alguna vez? $\square$ Sí $\square$ No Si ha contestado “Sín”, especifique motivo:

¿Se ha automedicado alguna vez? $\square$ Sí $\square$ No

¿Ha tomado antibióticos sin prescripción médica alguna vez? $\square$ Sí $\square$ No

¿Ha vacunado a sus hijo/os cumpliendo con el calendario vacunal? $\square$ Sí $\square$ No Si ha contestado "No",

especifique el motivo:

\section{Datos sobre hábitos alimentarios y estilo de vida:}

La persona encargada de elaborar el menú diario en su hogar es: $\square$ usted $\quad \square$ conyugue $\square$ Otros A diario almuerza en: $\square$ En casa $\square$ En la calle $\square$ Otros

A diario, el almuerzo en el hogar familiar consiste en:

Primer plato (verdura, ensalada) + Segundo plato (carne, pescado o guiso) + Postre (Fruta)

Plato único (carne, pescado, guiso) + Postre (lacteo)

Plato único (carne, pescado, guiso)

De entre las siguientes tomas de alimento cuáles realiza a diario y de forma regular:

Desayuno

Media mañana

Comida/almuerzo

Merienda

Cena

Existe alguien en su familia en situación de sobrepeso/obesidad (por favor marque lo que proceda):

Padre

$\square$ Madre

Hermanos

Hijos

¿Cómo considera que se encuentra respecto a su peso actual?
Delgado /a
Normal
Sobrepeso
Obeso /a

¿Cómo considera su estilo de vida? 
$\square$ Muy Saludable $\square$ Saludable $\square$ Poco saludable $\square$ Nada saludable

¿Conoce los riesgos en salud derivados de una mala alimentación?

$$
\text { Sí } \square \text { No }
$$

¿Ha practicado alguna vez una dieta milagro para perder peso rápidamente?

$$
\square \text { Sí } \square \text { No }
$$

¿Posee miedo a ganar peso?
Nunca
Algunas veces
Siempre
$\square$ Pánico a ganar peso

¿Pérdida de peso reciente en los últimos 3 meses?

$\square$ pérdida de peso > $3 \mathrm{~kg} \quad \square$ no lo sabe $\square$ pérdida de peso entre 1 y $3 \mathrm{~kg} \quad \square$ no ha habido pérdida de peso

¿Consume bebidas alcohólicas?

Nunca $\square \quad$ Los fines de semana $\square \quad$ Todos los días de la semana $\square \quad$ Esporádicamente

Edad de inicio del consumo de alcohol:

¿Eres consumidor/a de tabaco?

Nunca $\square \quad$ Los fines de semana $\square \quad$ Todos los días de la semana $\square \quad$ Esporádicamente $\square$

Edad de inicio del consumo de tabaco:

¿Consume algún tipo de droga ilegal?

Sí $\square \quad$ No $\square$

Si ha marcado "Si" en la pregunta anterior, indique por favor, que sustancia de las que a continuación se indican:

\section{Cánnabis $\square$ Cocaína $\square$ Heroína $\square$ Otras drogas sintéticas}

Indique, por favor, (en número) la frecuencia de consumo de estas sustancias:

$\mathrm{N}^{\mathrm{o}}$ veces día: $\mathrm{N}^{\circ}$ veces semana: $\mathrm{N}^{\circ}$ veces mes:

$\underline{\text { Sobre práctica de actividad física: }}$

- ¿Considera importante el ejercicio físico?

$\square$ Nada $\square$ Regular $\square$ Bastante 
- ¿Cuánto tiempo dedica a la práctica de ejercicio físico al día?
Ninguno
30 minutos
45 minutos
60 minutos
$\square$ Más de 60 minutos

- ¿Le gustaría dedicar más horas a la práctica de ejercicio físico a la semana?

$\square$ Nada $\square$ Regular $\square$ Bastante $\square$ Indiferente

- Durante su tiempo libre, ¿Permanece sentado, viendo la TV, etc?

Sí $\square$ No Si ha contestado "Sí", especifique cuántas horas al día:

$\underline{\text { Sobre sueño/descanso }}$

Horas de sueño diarias:
$<7$ horas
$\square$-8 horas
8 horas

Por favor, especifique con qué frecuencia consume los alimentos que figuran en la siguiente tabla:

\begin{tabular}{|l|l|l|l|}
\hline GRUPOS DE ALIMENTOS & Nunca & $\begin{array}{c}\mathbf{N}^{\mathbf{o}} \text { Veces } \\
\text { día }\end{array}$ & $\begin{array}{c}\mathbf{N}^{\mathbf{o}} \text { Veces } \\
\text { semana }\end{array}$ \\
\hline LECHE Y DERIVADOS & & & \\
\hline Leche & & & \\
\hline Derivados de la leche (yogurt, flan, ...) & & & \\
\hline FRUTAS & & & \\
\hline Frutas (naranja, mandarina, manzana, pera, plátano,...) & & & \\
\hline VERDURAS & & & \\
\hline $\begin{array}{l}\text { Verdura en general (Judías, lechuga, espinacas, tomate, } \\
\text { zanahoria) }\end{array}$ & & & \\
\hline CEREALES & & & \\
\hline Pan (Blanco, integral, molde) & & & \\
\hline Cereales desayuno & & & \\
\hline Pasta (macarrones, espaguetis, ...) & & & \\
\hline LEGUMBRES & & & \\
\hline Legumbres (garbanzos, lentejas, judías,...) & & & \\
\hline CARNES & & & \\
\hline Carne de pollo & & & \\
\hline Carne de pavo & & & \\
\hline Carne de cerdo & & & \\
\hline Carne de ternera & & & \\
\hline Jamón serrano, york & & & \\
\hline $\begin{array}{l}\text { Embutidos elaborados con cerdo (salchichón, mortadela y } \\
\text { chorizo) }\end{array}$ & & & \\
\hline Embutidos Halal & & & \\
\hline PESCADOS & & & \\
\hline Pescado blanco (merluza, mero, ...) & & \\
\hline
\end{tabular}




\begin{tabular}{|l|l|l|l|}
\hline Pescado azul (sardinas, atún, salmón, ...) & & & \\
\hline HUEVOS & & & \\
\hline Huevo de gallina & & & \\
\hline DULCES Y BOLLERÍA INDUSTRIAL & & & \\
\hline (Chocolates, bombones, kit - kat, y derivados) & & & \\
\hline (Croissant, donuts, bizcocho, y derivados) & & & \\
\hline Golosinas, snaks, caramelos, ... & & & \\
\hline AGUA Y BEBIDAS CARBONATADAS & & & \\
\hline Bebidas azucaradas (cola, limón, naranja...) & & & \\
\hline Zumo de Frutas (natural) & & & \\
\hline Zumo de Frutas (artificial) & & & \\
\hline Agua natural & & & \\
\hline OTROS & & & \\
\hline Alimentos precocinados (Lasañas, canelones, ...) & & & \\
\hline Salsas Industriales o de paquete (mayonesa, ketchup, alioli, ...) & & & \\
\hline
\end{tabular}

Procesos Culinarios (exprese por favor, la frecuencia de cada uno de ellos):

\begin{tabular}{|l|l|l|l|}
\hline & Nunca & Veces día & Veces semana \\
\hline Fritos / empanados & & & \\
\hline Plancha / asado / al horno & & & \\
\hline Salsas de elaboración casera & & & \\
\hline Cocido o al vapor & & & \\
\hline
\end{tabular}

Cuántas veces al mes realiza alguna de estas actividades:

\begin{tabular}{|l|l|}
\hline Actividad & Veces/mes \\
\hline Actividades físicas o deportivas & \\
\hline Actividades sedentarias (ver TV, etc) & \\
\hline Actividades de ocio (bricolaje; ganchillo, etc) & \\
\hline Actividades culturales (teatro, cine, leer...) & \\
\hline Actividades sociales (tomar una caña, ir al bar...) & \\
\hline Hecer turismo & \\
\hline Ir a actos religiosos & \\
\hline Participar en actividades de voluntariado & \\
\hline Usar las nuevas tecnologías & \\
\hline Actividades educativas (cursos, clases...) & \\
\hline
\end{tabular}

(***) No realiza actividad alguna

En qué medida diría usted que le interesa la política, en una escala de 1 al 10.

\begin{tabular}{|l|l|l|l|l|l|l|l|l|l|}
\hline 1 & 2 & 3 & 4 & 5 & 6 & 7 & 8 & 9 & 10 \\
\hline
\end{tabular}

Me podría decir si en las últimas elecciones...

\begin{tabular}{|l|l|}
\hline Fue a votar y votó & \\
\hline Fue a votar, pero no pudo hacerlo & \\
\hline No fue a votar porque no pudo & \\
\hline Prefirió no votar & \\
\hline No recuerda & \\
\hline NS/NC & \\
\hline
\end{tabular}


Se considera usted religioso/a

$\mathrm{Si}$

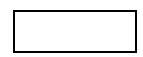

No

$\mathrm{Ns} / \mathrm{Nc}$

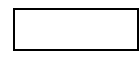

Se considera practicante o no practicante de su religión

$\mathrm{Si}$

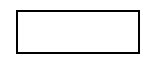

No

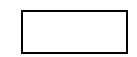

$\mathrm{Ns} / \mathrm{Nc}$

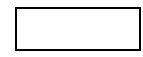

Pertenece usted a alguna asociación, ONG u organización

$\mathrm{Si}$

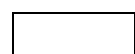

No

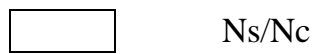

Si ha contestado que si, ¿cuál?

Con respecto a su nivel de renta como se considera usted, teniendo en cuenta que 1 equivale a muy pobre y 10 a muy rico.

\begin{tabular}{|l|l|l|l|l|l|l|l|l|l|}
\hline 1 & 2 & 3 & 4 & 5 & 6 & 7 & 8 & 9 & 10 \\
\hline
\end{tabular}

Bien, nos ha contado algunas cosas sobre usted, ahora nos gustaría conocer, con respecto a su relación con los Servicios Sociales, alguna cosa más. Por ejemplo:

¿Es la primera vez que acude al Centro de Servicios Sociales?

(1) SI (Pág. 8)

(2) NO

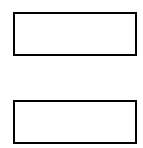

¿Podría decirme cuando fue la primera vez que acudió al Centro?

- $\quad$ Hace 6 meses (1)

- 1 año (2)

- $\quad 2$ años (3)

- $\quad 3$ años (4)

- $\quad 4$ años (5)

- $\quad 5$ años (6)

- $\quad+$ de 5 años (7)

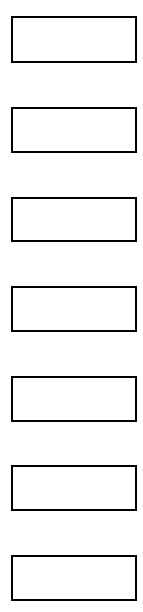

- $\mathrm{Ns} / \mathrm{Nc}$

¿Podría decirnos cuántas veces acude al Centro de Servicios Sociales? Número de veces

¿Cómo ha conocido la existencia de este Centro de Servicios Sociales?

(1) A través de familiares, amigos o vecinos

(2) A través de los servicios de la Ciudad Autónoma 
(3) A través de otros servicios públicos (hospitales, policía, colegios, etc.)

(4) A través de organizaciones, asociaciones o fundaciones

(5) A través de los medios de comunicación

(6) Otras formas ....

Especificar

¿Podría indicarme el motivo o motivos de su visita al Centro?

\begin{tabular}{|l|}
\hline Motivo 1 \\
\hline Motivo 2 \\
\hline Motivo 3 \\
\hline Motivo 4 \\
\hline Motivo 5 \\
\hline
\end{tabular}

¿El motivo de su visita o visitas al Centro se refiere a usted o a otra persona?

1.- Es para usted mismo/a

2.- Es para un hijo/a menor de edad

3.- Es para su padre/madre

4.- Es para otra persona de su familia

5.- Es para varios miembros de su familia

6.- $\mathrm{Ns} / \mathrm{Nc}$

¿Está usted o alguien de su familia disfrutando actualmente de algún tipo de ayuda, prestación, centro o servicio social de los que a continuación se especifican?

\begin{tabular}{|l|l|l|l|}
\hline \multicolumn{1}{|l|}{$\begin{array}{l}\text { Atención y seguimiento de su situación por un trabajador } \\
\text { social }\end{array}$} & Entrevistado & Familia & Desde cuando \\
\hline Ayuda a domicilio & & & \\
\hline Teleasistencia & & & \\
\hline $\begin{array}{l}\text { Ayudas económicas (comedor, escuela infantil, gastos } \\
\text { básicos) }\end{array}$ & & & \\
\hline Centro de día & & & \\
\hline Renta mínima de inserción & & & \\
\hline Otra. Cual/es & & & \\
\hline & & & \\
\hline No es beneficiario de ninguna atención, ayuda, etc.. & & & \\
\hline
\end{tabular}

\section{MUCHAS GRACIAS.}




\section{ANEXO II: Pesos de raciones de cada grupo de alimentos y medidas caseras. (SENC, 2004).}

\begin{tabular}{|c|c|c|c|}
\hline Grupos de alimentos & $\begin{array}{l}\text { Frecuencia } \\
\text { recomendada }\end{array}$ & $\begin{array}{l}\text { Peso de cada ración } \\
\text { (en crudo y neto) }\end{array}$ & Medidas caseras \\
\hline $\begin{array}{l}\text { Patatas, arroz, pan, pan } \\
\text { integral y pasta }\end{array}$ & $\begin{array}{l}4-6 \text { raciones al dia } \\
\uparrow \text { formas integrales }\end{array}$ & $\begin{array}{l}60-80 \mathrm{~g} \text { de pasta, arroz } \\
40-60 \mathrm{~g} \text { de pan } \\
150-200 \mathrm{~g} \text { de patatas }\end{array}$ & $\begin{array}{l}1 \text { plato nomal } \\
3-4 \text { rebanadas o un panecillo } \\
1 \text { patata grande o } 2 \text { pequeñas }\end{array}$ \\
\hline Verduras y hortalizas & $\geq 2$ raciones al día & $150-200 \mathrm{~g}$ & $\begin{array}{l}1 \text { plato de ensalada variada } \\
1 \text { plato de verdura cocida } \\
1 \text { tomate grande, } 2 \text { zanahorias }\end{array}$ \\
\hline Frutas & $\geq 3$ raciones al dia & $120-200 \mathrm{~g}$ & $\begin{array}{l}1 \text { pieza mediana, } 1 \text { taza de cerezas, } \\
\text { fresas..., } 2 \text { rodajas de melón... }\end{array}$ \\
\hline Aceite de oliva & 3-6 raciones al día & $10 \mathrm{ml}$ & 1 cucharada sopera \\
\hline Leche y derivados & 2-4 raciones al día & $\begin{array}{l}200-250 \mathrm{ml} \text { de leche } \\
200-250 \mathrm{~g} \text { de yogur } \\
40-60 \mathrm{~g} \text { de queso curado } \\
80-125 \mathrm{~g} \text { de queso fresco }\end{array}$ & $\begin{array}{l}1 \text { taza de leche } \\
2 \text { unidades de yogur } \\
2-3 \text { lonchas de queso } \\
1 \text { porción individual }\end{array}$ \\
\hline Pescados & 3-4 raciones a la semana & $125-150 \mathrm{~g}$ & 1 filete individual \\
\hline $\begin{array}{l}\text { Carnes magras, aves y } \\
\text { huevos }\end{array}$ & $\begin{array}{l}\text { 3-4 raciones de cada a } \\
\text { la semana. Alternar su } \\
\text { consumo }\end{array}$ & $100-125 \mathrm{~g}$ & $\begin{array}{l}1 \text { filete pequeño, } 1 \text { cuarto de pollo } \\
\text { o conejo, } 1-2 \text { huevos }\end{array}$ \\
\hline Legumbres & 2-4 raciones a la semana & $60-80 \mathrm{~g}$ & 1 plato normal individual \\
\hline Frutos secos & 3-7 raciones a la semana & $20-30 \mathrm{~g}$ & 1 puñado o ración individual \\
\hline $\begin{array}{l}\text { Embutidos y carnes } \\
\text { grasas }\end{array}$ & Ocasional y moderado & & \\
\hline Dulces, snacks, refrescos & Ocasional y moderado & & \\
\hline $\begin{array}{l}\text { Mantequilla, margarina y } \\
\text { bolleria }\end{array}$ & Ocasional y moderado & & \\
\hline Agua de bebida & 4-8 raciones al dia & $200 \mathrm{ml}$ aprox. & 1 vaso o 1 botellin \\
\hline Cerveza o vino & $\begin{array}{l}\text { Consumo opcional } \\
\text { y moderado en aduitos }\end{array}$ & $\begin{array}{l}\text { Vino: } 100 \mathrm{ml} \\
\text { Cerveza: } 200 \mathrm{ml}\end{array}$ & 1 vaso o 1 copa \\
\hline Práctica de actividad fisica & Diario & $>30$ minutos & \\
\hline
\end{tabular}

